\title{
CAPSULES FROM PICKERING EMULSION TEMPLATES
}

\author{
Ana Maria Bago Rodriguez* and Bernard P. Binks* \\ Department of Chemistry and Biochemistry, University of Hull, Hull, HU6 7RX, U.K.
}

Submitted to: $\quad$ Current Opinion in Colloid and Interface Science on 13.6.19; revised 16.9.19

$\begin{array}{ll}\text { *Proofs and correspondence to: } & \text { Professor B.P. Binks } \\ & \underline{\text { b.p.binks@ @ull.ac.uk }} \\ & \text { Dr. A.M. Bago Rodriguez } \\ & \underline{\text { a.bago-rodriguez@hull.ac.uk }}\end{array}$ 


\begin{abstract}
Following the resurgence of interest in particle-stabilised or Pickering emulsions recently, the preparation of capsules from such templates has become feasible. We review some of the recent activity in this area and focus on both the methods used to reinforce the particle shell and the applications of these novel capsules, which may be empty or liquid-filled. The methods reported include interfacial polymerisation or crystallisation, interfacial cross-linking, the use of a sacrificial template, formation of polymer layers, gelation and evaporation from multiple emulsions. Potential applications are in the areas of wastewater treatment, perfume encapsulation, drug/dye release and as self-healing coatings.
\end{abstract}




\section{Introduction}

A microcapsule is a hollow microparticle composed of a solid shell surrounding a core-forming space available to permanently or temporarily entrap substances [1]. Encapsulation of gases or liquids is widely applied in food [2], pharmaceutical [3] and cosmetic products [4]. One of the reasons for their widespread use is to protect the active ingredient from the external environment, e.g. to avoid the oxidation of vitamins or to protect enzymes from denaturing solvents [5]. They can also encapsulate a substance which can be released either instantaneously once the external conditions are suitable or in a controlled/sustained manner. The contents of the capsules can be released immediately to the external medium upon shell rupture through an applied shear or pressure or by its dissolution. For a sustained release profile, the shell must be either permeable to allow the diffusion of the encapsulated material or must be designed so it can be reversibly modified upon changing the conditions of the external medium ( $\mathrm{pH}$, ionic strength, light or temperature) [6]. In addition, due to their hollow nature these capsules possess high surface areas, making them suitable to use as catalysts and sensors and in separation and storage materials [7]. The structural characteristics of these capsules (size, surface chemistry, shell permeability etc.) have to be well-engineered so they can be successfully implemented for each particular case.

Capsule shells can be prepared from polymers. One method consists in depositing polymer layers onto inorganic templates, followed by template removal. An alternative method, known as polymer growth by surface polymerisation, consists of using colloidal particles whose surface is modified with a polymer used as a seed for polymerisation. Subsequent polymer cross-linking creates the core-shell structure. These two methods cannot be used for encapsulating liquid cores however. Instead, copolymer vesicles (or polymersomes) and the use of emulsions as templates are reported. As the formation of capsules from polymers is quite broad and these methods are not in the scope of this brief review, we cite various recent reviews where these systems are discussed [7-10].

Capsules can also be prepared from Pickering emulsions, which are emulsions stabilised by solid particles. The formation of these capsules first involves the preparation of a Pickering emulsion followed by a shell reinforcement mechanism to lock the particles at the liquid-liquid interface. In 1996, Velev and co-workers described the self-assembly of polystyrene latex particles using $n$-octanol droplets in water as a template [11,12]. Latex particles, whose surfaces were previously modified with lycine, were used as the emulsifier to produce an oil- 
in-water $(\mathrm{o} / \mathrm{w})$ emulsion. Afterwards, casein was added to the continuous phase followed by a mixture of $\mathrm{HCl}$ and $\mathrm{CaCl}_{2}$ that act as coagulants for the latex particles. This additional reinforcement allowed the microcapsules to maintain their structure upon removal of $n$-octanol by dissolution with ethanol. The term colloidosome was coined by Dinsmore et al. [13] by analogy with liposomes (self-assembled vesicles from amphiphilic lipids) and it is generally used to refer to capsules prepared from Pickering emulsions. They first prepared an o/w emulsion stabilised by carboxylated polystyrene latex particles, followed by locking the particles together either by addition of polycations, by van der Waals forces or by sintering [13]. Other methods to reinforce the particle shell have been reported since then, which will be described here in detail and are summarised in Table 1. Various particle types $\left(\mathrm{SiO}_{2}, \mathrm{TiO}_{2}\right.$, $\mathrm{ZnO}, \mathrm{Al}_{2} \mathrm{O}_{3}, \mathrm{CaCO}_{3}$, polymer latex...) of different shapes (spheres, rods, cubes...) have been used. As the sizes of these particles are in the nanometer to micrometer range, the obtained Pickering emulsions and hence the final capsules are generally micron-sized.

This review includes recent examples for the preparation of capsules from Pickering emulsions, being an update of other reviews discussing either this specific topic $[14,15]$ or the fabrication of hollow materials with colloids from a broader perspective [16]. Unlike other reviews in the area, the classification here is based on the nature of the capsule core: empty capsules (gasfilled) or liquid-filled capsules. Capsules containing a solid core are not included as they do not satisfy the capsule definition. The core (and not the interface) is solidified, so solid beads instead of hollow entities arise. These structures are prepared through Pickering emulsion polymerisation [17]. For each class of capsule, different methodologies for the rigidification of the interface are presented. Experiments dealing with encapsulation and subsequent release of an active are described alongwith their applications in fields such as wastewater treatment, medicine, corrosion protection and electrochemistry.

\section{Empty capsules}

\section{(a) Interfacial polymerisation}

This section refers to capsules obtained by interfacial polymerisation in which the monomer(s) is either in water or in oil. Zhang et al. [18] prepared polyacrylamide/silica $\left(\mathrm{PAM} / \mathrm{SiO}_{2}\right)$ composite capsules from a water-in-oil (w/o) Pickering emulsion. An aqueous phase containing acrylamide, $N, N$-methylenebisacrylamide and ammonium persulfate was homogenised into liquid paraffin using silane-modified silica nanoparticles. The w/o emulsion so-obtained was subsequently polymerised at $72{ }^{\circ} \mathrm{C}$ for $24 \mathrm{~h}$. As the molecular weight of the polymer in water 
droplets increases upon polymerisation, its solubility in water decreases. As a result, the polymer precipitates from the water phase and adsorbs on the surface of the stabilising silica particles eventually forming a polyacrylamide layer. The droplets were filtered, washed with water and ethanol and dried under vacuum at $60{ }^{\circ} \mathrm{C}$. Smaller capsules were achieved by increasing the silica particle concentration, in agreement with the limited coalescence model for particle-stabilised emulsions [19] and the rigidity of the composite $\mathrm{PAM} / \mathrm{SiO}_{2}$ layer was dependent on the acrylamide concentration. These capsules were found to be a good candidate for the absorption of $\mathrm{Hg}(\mathrm{II})$ ions and could potentially be used for removing heavy metals ions in wastewater. In $30 \mathrm{~min}, 90 \%$ of $\mathrm{Hg}$ (II) was removed from an aqueous $\mathrm{HgSO}_{4}$ solution containing the composite capsules while that obtained with capsules of PAM alone was $<20 \%$ (Figure 1(a)). The higher adsorption capacity of $\mathrm{PAM} / \mathrm{SiO}_{2}$ composite capsules could be due to the larger adsorption volume of the hollow capsules compared with those of pure PAM. Moreover, the capsules could be regenerated and re-used up to five times after extracting the absorbed $\mathrm{Hg}(\mathrm{II})$ with acetic acid.

Chen et al. [20] prepared organic-inorganic hybrid hollow capsules from Pickering emulsions stabilised with $\mathrm{TiO}_{2}$ nanoparticles. The oil $n$-hexadecane containing styrene, divinylbenzene (DVB) and an initiator was emulsified into an aqueous phase containing the nanoparticles. The obtained o/w emulsion was polymerised overnight at $51{ }^{\circ} \mathrm{C}$. After drying and removing the solvents, hybrid hollow spheres consisting of $\mathrm{TiO}_{2}$ nanoparticles and poly(styrene-co-DVB) were obtained (Figure 2(a)). Hexadecane is a non-solvent for the polymer so it phase separates towards the interface of emulsion droplets to form the composite wall. By increasing the amount of DVB the mechanical stability was enhanced, and smaller capsules were obtained by decreasing the volume fraction of oil. Although no encapsulation and release experiments were reported, potential applications were suggested including as carriers for drug release systems or as catalytic materials for chemical reactions. Bon et al. [21] prepared an o/w emulsion with an oil phase similar to that just mentioned but stabilised by latex particles of poly(methyl methacrylate) in the aqueous phase. After emulsion preparation, radical polymerisation was initiated by heating to $60{ }^{\circ} \mathrm{C}$. The capsule flexibility could be tailored by varying the crosslinking degree of the scaffolding and by introducing $n$-butylmethacrylate as a co-monomer. Another variation of the same experimental design is given by Chen et al. [22]. The oil $n$ octadecane containing monomer, crosslinker and initiator was homogenised into an aqueous dispersion containing $\mathrm{ZnO}$ nanoparticles rendering an o/w emulsion. After polymerisation at $55^{\circ} \mathrm{C}$ for 30 min followed by solvent evaporation, capsules with a diameter between 5 and 30 
$\mu \mathrm{m}$ and a shell thickness between 200 and $500 \mathrm{~nm}$ were obtained (Figure 2(b)). As the $n$ octadecane content in the oil phase increased, the microcapsules were more fragile because of thinner polystyrene walls. The drying method also played an important role in maintaining the microcapsule structure, with freeze-drying being more effective than conventional drying at room temperature. The photoluminescence behaviour of the polystyrene/ $\mathrm{ZnO}$ hybrid microcapsules was assessed and found to be unchanged compared to that of pristine $\mathrm{ZnO}$. These microcapsules could therefore be applied as chemical sensors and in optoelectronics.

Zhang et al. [23] prepared magnetic hollow capsules with shells composed of modified silica particles and a layer of polymer entrapping $\mathrm{Fe}_{3} \mathrm{O}_{4}$ nanoparticles. The oil phase containing monomer, crosslinker, initiator and hydrophobic $\mathrm{Fe}_{3} \mathrm{O}_{4}$ nanoparticles was homogenised into an aqueous phase containing silica particles to form an $\mathrm{o} / \mathrm{w}$ emulsion. Upon polymerisation at $78^{\circ} \mathrm{C}$ for $24 \mathrm{~h}$, polymer chains reached a critical length and phase separated from $n$-hexadecane droplets to the oil-water interface due to their low solubility in oil. These capsules were superparamagnetic, i.e. they are attracted to a magnetic field but retain no residual magnetism when the magnetic field is removed. Hence, they could have interesting applications as drug carriers. To probe their applicability in drug delivery, a drug release experiment was carried out by encapsulating Ibuprofen. Capsules containing the drug were introduced into a phosphate buffer solution. The release medium penetrated into the drug-loaded space through the interstices in the capsule wall, allowing drug molecules to dissolve in it and then diffuse out from the carrier. Almost $40 \%$ of Ibuprofen was released after $10 \mathrm{~min}$, while the rest was dissolved slowly following a typical sustained release pattern; after 4.7 days, $80 \%$ of Ibuprofen was released.

Yang et al. [24] prepared capsules containing smaller capsules inside. Both kinds of capsule were formed from a Pickering emulsion template. For the preparation of the inner capsules, hydrophilic fumed silica was dispersed in water and homogenised with an oil phase containing dibutyl phthalate (DBP), isophorone diisocyanate (IPDI) and a cross-linker. Diethylenetriamine (DETA) was added to the formed $\mathrm{o} / \mathrm{w}$ emulsion to initiate interfacial polymerisation between IPDI in the oil phase and DETA in the aqueous phase. Unlike the previous examples, polymerisation occurs exclusively at the interface via the interaction of components dissolved in different phases. A polyurea (PU) shell was thus obtained around oil droplets. In a subsequent step, capsules clusters were prepared. PU capsules prepared as above were mixed with a pre-polymer of melamine and formaldehyde (pre-MF) in water and this aqueous phase was homogenised with toluene using hydrophobic fumed silica particles as 
emulsifier. The w/o emulsion obtained contained PU capsules in the water drops. Polymerisation in situ of pre-MF at $70{ }^{\circ} \mathrm{C}$ resulted in a PMF shell at the water-oil interface. The size of the capsule clusters could be controlled by adjusting the oil:water ratio. The coencapsulated inner capsules can act as separate compartments for a synergistic delivery of incompatible actives or chemicals or as micro-reactor vessels for biochemical/chemical reactions. Sudan I was encapsulated in the PU capsules. Capsule clusters were added to different solvents (tetrahydrofuran (THF), ethanol, hexane, water) and the diffusion of the dye was followed by UV absorbance. The diffusion profile of Sudan I was fast in ethanol and THF with a cumulative diffusion fraction of $96.3 \%$ and $84.1 \%$ respectively after $1 \mathrm{~h}$. The diffusion of Sudan I into hexane was very slow as the hydrophobic oil cannot wet the capsule clusters. No diffusion of Sudan I into water was observed. Although water can wet the capsule clusters, Sudan I cannot diffuse into water being insoluble.

Wang et al. [25] recently compared the mechanical properties of hollow capsules prepared from interfacial reactions between isocyanate in oil and amino-functionalised $\mathrm{SiO}_{2}$ nanoparticles in o/w Pickering emulsions to those prepared from Pickering emulsion templates with UV-curable resin in the oil phase and acrylate-functionalised $\mathrm{SiO}_{2}$ nanoparticles. Despite their importance, the mechanical properties of capsules are scarcely reported so far. For the latter capsules, interfacial polymerisation occurred by illuminating the Pickering emulsion with a $365 \mathrm{~nm}$ laser. After photopolymerisation, the capsules were washed with ethanol and dried under vacuum. Capsules with UV-curable resin had much thicker shells and stronger mechanical properties. Moreover, by changing the resin content, the mechanical strength could be finely adjusted.

\section{(b) Polymerisation}

Huo and co-workers [26] prepared capsules from a Pickering emulsion via UV-induced polymerisation. Water and immiscible photosensitive oligomer indicated in Table 1 were mixed with $\mathrm{Al}_{2} \mathrm{O}_{3}$ nanoparticles hydrophobised in situ with pentanoic acid as emulsifier yielding a w/o emulsion. Water was then added to the emulsion and the mixture was stirred to form unstable oil globules containing multiple water droplets, i.e. a w/o/w emulsion. The latter was rapidly cured with UV light at $405 \mathrm{~nm}$ and water was subsequently removed. As a result, a capsule containing multiple voids is obtained after sintering. Here, both interfacial polymerisation and polymerisation of the middle oil phase occur. These capsules are interesting 
for a rapid and cost effective synthesis of high-output ceramic capsule materials. Potential applications are in the fields of adsorption, load and release of materials and thermal insulation.

\section{(c) Liquid marbles}

Zhang and Wang [27] presented an interesting and different approach to prepare capsules. First they prepared a w/o emulsion by mixing an oil phase of dichloromethane (DCM) containing poly(L-lactic acid) and partially hydrophobic silica particles with pure water. The obtained emulsion was transferred drop by drop into a petri dish containing the same silica particles, followed by immediate rolling to form stable oil liquid marbles. These macroscopic oil marbles contained water drops inside with both interfaces covered with the same kind of silica particles. The marbles were dried at room temperature (with polymer adhering to inner/outer interfaces) and cellular capsules were obtained upon complete evaporation of DCM and water. A schematic of all the steps for capsule formation is given in Figure 3(a). In this case the size of the capsules was larger (few $\mathrm{mm}$ in diameter) compared to those obtained from more traditional approaches. A drug release experiment was carried out by encapsulating Enrofloxacin, a common bactericide for animals, initially dissolved in the oil phase. The cellular capsule containing the drug was placed into water at $37^{\circ} \mathrm{C}$, and after specific periods of time an aliquot was withdrawn from the release medium and analysed by UV-vis spectrophotometry. $36 \%$ of the drug was released during the first $50 \mathrm{~h}$. After this period, the release rate became slow until it reached a plateau at $42 \%$. Therefore, these capsules displayed sustained drug release and due to the biodegradability and biocompatibility of poly(L-lactic acid) and silica particles respectively, they are potential candidates in biomedicine.

\section{(d) Sacrificial template}

Strohm and Löbmann [28] prepared porous $\mathrm{TiO}_{2}$ capsules by liquid phase deposition on polystyrene (PS) latex-stabilised Pickering emulsions. To prepare an o/w emulsion, 1-octanol was emulsified into an aqueous phase containing a mixture of PS microparticles coated sequentially with a layer of PDADMAC (cationic) and then a layer of PAA (anionic) polyelectrolytes. For the liquid phase deposition step, the emulsion was poured into a solution containing $\left(\mathrm{NH}_{4}\right)_{2}\left[\mathrm{TiF}_{6}\right]$ and $\mathrm{H}_{3} \mathrm{BO}_{3}$ and after a period of time a film of $\mathrm{TiO}_{2}$ was formed around the PS particles in the emulsion template (Figure 3(b)). Afterwards, PS particles were removed by treatment with toluene and calcination removed the oil, leading to porous hollow spheres (Figure 2(c)). Depending on the calcination temperature, either micropores (diameter 
$<3 \mathrm{~nm}$ ) or mesopores (diameter $=4-50 \mathrm{~nm}$ ) were formed. The inorganic hollow spheres showed photocatalytic activity. Degradation of dichloroacetic acid (DCA) was studied as a model substance for chloro-organic wastewater pollutants to evaluate the potential use of these capsules as a suspended catalyst for photocatalytic water purification. The hollow spheres were dispersed in an aqueous solution containing DCA. Upon UV radiation, a linear increase in chloride concentration was recorded for capsules prepared at different calcination temperatures (Figure 1(b)). The highest photocatalytic activity was achieved when capsules contained pores in the size range $1-4 \mathrm{~nm}$.

Unlike other papers cited in this review, $\mathrm{Xu}$ et al. [29] prepared $\mathrm{Au}$ and $\mathrm{Pt}$ open-mouthed hollow capsules from Pickering emulsion templates. Here, $\mathrm{Cu}_{2} \mathrm{O}$ particles of various shapes (spheres, cubes and octahedra) were used as the particulate emulsifier dispersed in water. Paraffin wax was used as the oil phase. Emulsification was carried out at $70{ }^{\circ} \mathrm{C}$ after which the emulsion was cooled to room temperature to solidify the core of the $\mathrm{o} / \mathrm{w}$ emulsion. The particlecoated wax beads were subsequently added to a polymer solution and either $\mathrm{HAuCl}_{4} \mathrm{Or}_{2} \mathrm{PtCl}_{6}$ solution was slowly added into the suspension. A galvanic reaction took place and the surface of the $\mathrm{Cu}_{2} \mathrm{O}$ particles in contact with the aqueous continuous phase ended up coated by a film of either Au or Pt. After $12 \mathrm{~h}$, the products were washed with tetrahydrofuran to remove the wax and $\mathrm{Cu}_{2} \mathrm{O}$ residues were removed with $\mathrm{HCl}$ (Figure 3(c)). As a result, various openmouthed Au or Pt hollow capsules were formed (Figure 2(d-f)). The catalytic activity of the open-mouthed hollow capsules was investigated by measuring the reduction of 4-nitrophenol through UV-vis spectrophotometry (Figure 1(c)). The performance was compared to that obtained with intact $\mathrm{Au}$ hollow capsules, prepared from a galvanic reaction using $\mathrm{Cu}_{2} \mathrm{O}$ nanoparticles as a sacrificial template (no emulsion). The catalytic performance of the openmouthed hollow capsules was superior as they could facilitate the diffusion of reactants to the inner side of the shell wall.

\section{(e) Multiple emulsion template}

Unlike other designs where spherical capsules were obtained, we highlight the work of Lee and Weitz [30]. Here, non-spherical colloidosomes with multiple compartments and different morphologies were prepared from w/o/w multiple emulsions using microfluidics. By controlling the flow rates of the three phases, multiple emulsions could be prepared containing different numbers of internal water drops within oil globules. The three phases were toluene containing hydrophobic silica nanoparticles and two aqueous phases containing poly(vinyl 
alcohol), PVA. Inner w/o droplets were stabilised by particles while the outer o/w interface was stabilised by PVA. Upon evaporation of the oil phase, the internal w-o interface retained its spherical shape whereas the outer o-w interface deformed, leading to the formation of nonspherical colloidosomes with multiple compartments. The morphology of the obtained colloidosome depended on the number of water droplets (n) in the multiple emulsion. For $\mathrm{n}=$ 2 , either ellipsoids or peanut-shaped colloidosomes were obtained, while for $n>2$, capsules of other geometries could be prepared (Figure 2(g)). As non-spherical particles can pack more densely than spherical ones, capsules with these geometries could be used to store a larger amount of encapsulated materials.

\section{(f) Cross-linking}

Sub-micron pH-responsive microgel (MG) colloidosomes were prepared by Wang et al. [31] from $\mathrm{o} / \mathrm{w}$ Pickering emulsions. The oil phase was ethyl acetate containing azobisisobutyronitrile $(\mathrm{AIBN})$ and the aqueous phase contained a buffer $(\mathrm{pH}=6.4)$ and $\mathrm{MG}$ particles. The MG particles were composed of ethyl acrylate and methacrylic acid with peripheral vinyl groups. These particles acted as the emulsion stabiliser and as a macro crosslinker. Using thermal free-radical coupling of surface vinyl groups, the MG particles adsorbed at the oil-water interface interlinked covalently. After MG cross-linking at the interface, ethyl acetate was removed by evaporation leaving hollow colloidosomes. The permeability was probed by introducing the capsules to FITC-dextran aqueous solutions of different molecular weights at three $\mathrm{pH}$. At pH 5.5 and 6.2, dextran polymers with molecular weights $\leq 40 \mathrm{~kg} \mathrm{~mol}^{-}$

${ }^{1}$ could permeate to the capsule interior. The pore size of the capsule shell at $\mathrm{pH}=6.2$ was estimated to be between 6.6 and $9.0 \mathrm{~nm}$. A pH = 7.4, however, none of the dextran polymers could diffuse to the capsule interior. At this $\mathrm{pH}, \mathrm{MG}$ colloidosomes became swollen with water and MG particles were fully intermeshed preventing solute penetration.

\section{Liquid-filled capsules}

\section{(a) Deposition of polymer layers}

Demina et al. [32] prepared capsules with shells composed of titanium dioxide nanoparticles and polyelectrolytes. They first prepared an o/w emulsion by mixing dodecane with an aqueous dispersion containing $\mathrm{TiO}_{2}$ nanoparticles partially hydrophobised with $n$-octadecylphosphonic acid (ODPA). Oppositely charged polyelectrolytes were subsequently deposited onto the emulsion droplets via layer-by-layer adsorption. Solutions of a polyanion (sodium polystyrene 
sulfonate, PSSNa) and a polycation (chitosan) were used. Since the surface of the precursor emulsion droplets was positively charged, PSSNa was deposited as the first layer. The feasibility of encapsulating functional compounds was studied by incorporating a fluorescent dye (Nile red) into the oil cores of the capsule. The photocatalytic activity of $\mathrm{TiO}_{2}$ particles present in the shell was probed. Under UV radiation the initial colloidal system lost its colour and the decolouration was recorded spectrophotometrically. As a control, capsules containing dodecane and Nile red and having shells formed from xanthan gum and chitosan were irradiated (no $\mathrm{TiO}_{2}$ ). The UV irradiation of these capsules did not result in the decolouration of the emulsion. Capsules composed of $\mathrm{TiO}_{2}$ nanoparticles are well-suited for the purification of wastewater containing oil-soluble impurities that are prone to photocatalytic decomposition in the presence of $\mathrm{TiO}_{2}$. Compounds such as organic peroxides, chloroform or other chlorinecontaining hydrocarbons could be decomposed under solar UV radiation.

Li and Stöver [33] prepared o/w emulsions stabilised by PSSNa-modified Ludox CL silica particles dispersed in water. Various oils of different polarities (xylene, perfluoroheptane, heptane, $n$-butyl acetate and chloroform) were used and stable emulsions were prepared in all cases. Afterwards, layer-by-layer assembly with PDADMAC and PSSNa was carried out. However, the microcapsules lost their encapsulated oil upon drying. In order to increase the encapsulation efficiency, negatively charged Ludox HS-30 particles were used to replace PSSNa as the anionic coating material. Despite the improved resistance towards breakage and a higher encapsulation efficiency, these microcapsules also fully collapsed upon dehydration by releasing the oil due to cracking of the capsule walls. However, this property could lead to applications that require dehydration-triggered release of the core contents like one-pot waterborne paints and adhesives.

The two examples given above are based on the layer-by-layer deposition of oppositely charged polyelectrolytes. A different approach, reported by Ao et al. [34], consists of the migration of polymer chains from the droplet core to the interface upon dilution (Figure 4(a1)). An o/w Pickering emulsion was first prepared stabilised by polystyrene latex particles coated with ionisable carboxylic acid groups. The oil droplets consisted of $n$-octanol, ethyl acetate (EA) and poly(lactic-co-glycolic acid), PLGA (which is soluble in EA but insoluble in water) while the aqueous phase was water saturated with $\mathrm{EA}$. The emulsion was then diluted with pure water. As EA is more miscible in water than in $n$-octanol, EA molecules diffuse to the continuous aqueous phase through the interstices between the assembled latex particles. As a consequence PLGA in the oil core (which is soluble in EA but insoluble in $n$-octanol) undergoes an outward 
transport getting entrained at the interface and locking the assembled particles. The formed microcapsules are good candidates for encapsulating hydrophobic actives and due to their simple preparation protocol they could easily be implemented industrially.

Radulova et al. [35] prepared microcapsules by combining a surface-active polymer and hydrophilic silica particles partially hydrophobized with a surfactant (potassium oleate). An aqueous solution containing the modified silica particles and polymer (Carbopol 971P) was mixed with an oil phase by sonication. The microcapsules so formed containing oil sedimented. The supernatant, comprising of excess of polymer, surfactant and particles was removed and the microcapsules were rinsed with water. Various oils and fragrances (tetradecane, limonene, benzyl salicylate and citronellol) were encapsulated by this method. It is posed that the interstices left between adsorbed particles at the oil-water interface are filled by a mixed layer of polymer and surfactant. At $\mathrm{pH}<6$, the adsorbed polymer blocked the dissolution of the encapsulated oil/fragrance in the aqueous phase and also prevented the desorption of surfactant molecules from particle surfaces. Microcapsules containing limonene dispersed in pure water at $\mathrm{pH}=5.5$ were stable for at least 8 months at $25^{\circ} \mathrm{C}$. However, upon increasing the $\mathrm{pH}$ above 6 , the increased negative electric charge of the polymer leads to its desorption into water, allowing surfactant molecules to migrate from the particle-oil interface into water. Consequently, particles turn hydrophilic, the capsule integrity breaks and the cargo is released.

\section{(b) Interfacial crystallisation}

Wang et al. [36] described an interesting approach to prepare capsules whose shells are composed of one single component (Figure 4(a2)). Pristine $\mathrm{CaCO}_{3}$ microparticles were used to emulsify sunflower oil into an aqueous phase at $\mathrm{pH}=8.5$ containing ammonia and ammonium chloride to form an o/w emulsion. The obtained emulsion was then put into a reactor and $\mathrm{CO}_{2}$ gas was introduced into the vessel. Aqueous $\mathrm{CaCl}_{2}$ was added to the emulsion as well as $\mathrm{NaOH}$ to control the $\mathrm{pH}$. The $\mathrm{CaCO}_{3}$ particles at the interface acted as nucleation sites for dissolved calcium and carbonate ions to form a dense $\mathrm{CaCO}_{3}$ shell (Figure 2(h)). The crystallisation process was controlled by regulating the gas flow rate and the $\mathrm{CaCl}_{2}$ concentration. These capsules were used for flavour encapsulation. Limonene was dissolved in the sunflower oil prior to capsule formation and both the encapsulation efficiency and the flavour release profile were measured. The encapsulated flavour molecules demonstrated a prolonged release profile for more than $40 \mathrm{~min}$, compared to the non-encapsulated case where the release occurred in less than $5 \mathrm{~min}$ in hot water. Moreover, capsules showed a triggered release in an acidic 
medium due to dissolution of the $\mathrm{CaCO}_{3}$ shell. Therefore, these capsules are good candidates as food grade capsules for controlling the flavour release or for masking the unpleasant taste of specific ingredients, which could be released in the stomach as the $\mathrm{pH}$ falls.

\section{(c) Gelation}

Gelation of the core of emulsion droplets was reported a while ago by Noble et al. [37]. Rodlike polymeric particles were used to prepare a w/o emulsion of hot aqueous agarose in tricaprylin. The emulsion was cooled to room temperature to set the agarose gel. The gelled beads with polymeric microparticles at the interface were separated from the oil and the surface of the colloidosomes was subsequently cross-linked with glutaraldehyde to improve the retention of the microrods on the surface. Gelation of the interface was reported more recently by Leong and co-workers [38]. Here, for the preparation of the Pickering emulsion, $\mathrm{CaCO}_{3}$ nanoparticles were used as the stabiliser of an o/w emulsion. Subsequently, a polyanionic biopolymer (sodium alginate, gellan gum or pectin) was added to the continuous aqueous phase. The $\mathrm{pH}$ was then reduced to dissolve the nanoparticles. As a result, the liberated $\mathrm{Ca}^{2+}$ ions cross-linked the biopolymer at the periphery of the oil droplets to form a continuous shell that enveloped the oil core (Figure 4(a3)).

The same chemistry was used by Marquis et al. [39] to prepare microcapsules that could encapsulate lipophilic compounds for food, cosmetic and medical applications. The initial o/w emulsion was prepared from hexadecane and an aqueous phase containing cellulose nanocrystals (CNC) and $\mathrm{CaCO}_{3}$ particles. The $\mathrm{CNC}$ were the particulate stabiliser while $\mathrm{CaCO}_{3}$ particles adsorbed onto the cellulose particle layer. Subsequently, oil droplets were encapsulated within alginate microgels in water using microfluidics. On adding acid, the $\mathrm{Ca}^{2+}$ ions liberated from $\mathrm{CaCO}_{3}$ particles on the outer layer of the droplets initiated alginate gelation. Monodisperse alginate microgels $(\mathrm{d} \sim 85 \mu \mathrm{m})$ containing around 12 oil droplets $(\mathrm{d} \sim 15 \mu \mathrm{m})$ were prepared. Nile red was encapsulated by dispersing it in hexadecane as a model lipophilic compound. No dye diffused outside the microcapsule for a few days after encapsulation. However, oil droplets containing the fluorescent dye could be released by addition of either sodium citrate (chelation of $\mathrm{Ca}^{2+}$ ions) or ethanol.

Ionic gelation in a different system was reported by Mwangi et al. [40]. They first prepared an $\mathrm{o} / \mathrm{w}$ emulsion stabilised by chitosan particles. The Pickering emulsion was then transferred to a solution containing sodium tripolyphosphate (TPP) and the $\mathrm{pH}$ was adjusted between 2 and 8.5. An electrostatic interaction occurred between the positively charged amino groups on 
chitosan particles and the negatively charged TPP ions. The microcapsules were then washed with water. The capsule mean size decreased from $137 \mu \mathrm{m}$ to $90 \mu \mathrm{m}$ by increasing the $\mathrm{pH}$ from 2 to 8.5. The formation of larger particles at low $\mathrm{pH}$ was explained by the swelling of the chitosan shell and/or the coalescence of microcapsules caused by the dissolution of the shell. The amount of oil released from the capsules prepared at different $\mathrm{pH}$ was measured. At $\mathrm{pH}<$ $\mathrm{p} K_{\mathrm{a}}$ of chitosan $(\sim 6.5)$, the amino groups on the polymer chains are protonated. Hence, electrostatic repulsion occurred leading to the swelling of the capsule shells. The amount of oil released was $\sim 40 \%$. On the contrary, for capsules prepared at $\mathrm{pH}>\mathrm{p} K_{\mathrm{a}}$ the amount of oil released decreased, being as low as $5 \%$ at $\mathrm{pH}=5$. By increasing the $\mathrm{pH}$, chitosan becomes deprotonated with some residual positively charged amino groups that cross-link with TPP. Hence, electrostatic repulsion decreases and this improves the integrity of the shell.

\section{(d) Multiple emulsion template}

San Miguel and co-workers [41] prepared capsules using a different approach. They prepared a multiple w/o/w emulsion that upon evaporation of the oil phase left a bilayer of particles held by van der Waals forces constituting the capsule shell encapsulating water in water (Figure 4(b)). A w/o emulsion was first prepared from an aqueous phase containing copolymer particles of methyl methacrylate and methacrylic acid dispersed in water and dichloromethane. At low $\mathrm{pH}$ the particles are uncharged so they aggregate, at high $\mathrm{pH}$ they dissolve and at intermediate $\mathrm{pH}$ they render a stable dispersion. Moreover, the particle wettability can be adjusted through charge screening. For the preparation of the initial w/o emulsion, $25 \mathrm{mM}$ of $\mathrm{NaCl}$ was required. Subsequently, the w/o/w emulsion was prepared by adding the w/o emulsion to an aqueous solution containing the same particles but with a higher concentration of $\mathrm{NaCl}(250 \mathrm{mM})$ and gentle shaking. Oil was then extracted by dilution and solvent evaporation at room temperature, enabling the particles at the outer interface to assemble with those of the inner interface. Due to the responsiveness of the capsules to $\mathrm{pH}$, a swift release of their contents could be effected by raising the $\mathrm{pH}$ from 4.5 to 8 .

Zhou et al. [42] prepared nanoparticle colloidosomes from multiple emulsion templates using microfluidics in which the encapsulated active could be released upon a change in temperature. This switchable release occurred due to the adsorption/desorption of a block copolymer dissolved in the capsule core, which blocks/unblocks the pores of the shell. For the preparation of the multiple w/o/w emulsion, the inner water phase consisted of an aqueous solution of a temperature-sensitive block copolymer (Pluronic L31), the oil phase was a fluorinated oil 
containing $\beta$-cyclodextrin nanoparticles (plus surfactant) and the outer phase was an aqueous dispersion containing PVA. Monodisperse multiple emulsion drops with each globule containing a single drop were obtained from the adsorption of the nanoparticles at the two interfaces. Upon evaporation of the external aqueous phase and the oil phase the nanoparticles bind with each other (and PVA) through hydrogen bonds and capsules of diameter $\sim 50 \mu \mathrm{m}$ with a shell thickness of $40 \mathrm{~nm}$ and pores of around $3 \mathrm{~nm}$ were prepared. A dye release experiment was carried out by dissolving sulforhodamine $\mathrm{B}$ in the aqueous phase prior to capsule formation and measuring the change in the fluorescence intensity of the colloidosome cores. At $21^{\circ} \mathrm{C}$ the block copolymer adsorbs at the surfaces of the colloidal particles closing the pores. As a result, the dye was fully encapsulated and fluorescence intensity did not change over 11 days. At $37^{\circ} \mathrm{C}$ however, the copolymer desorbs from particle surfaces opening the pores and releasing the dye. The florescence intensity in this case decreased over time.

\section{(e) Silica precursor}

The addition of a silica precursor to an emulsion stabilised by solid particles is another way of preparing capsules. In this case the rigidification is due to hydrolysis and condensation reactions at the oil-water interface. Moreover, if silica particles are the Pickering emulsion stabiliser, the shell of the obtained capsules will be all-silica (Figure 4(c)). Wang and coworkers [43] used hydrophobic silica nanoparticles to stabilise a w/o emulsion of aqueous $\mathrm{HCl}$ and toluene. After emulsification, a toluene solution containing hyperbranched polyethoxysiloxane (PEOS) was added. Particle hydrophobisation was carefully adjusted so that particles possessed free silanol groups available for reaction with PEOS. The emulsion was stirred for 3 days allowing complete hydrolysis of PEOS at the oil-water interface with reassembly of nanoparticles and PEOS solidification. As a result of the condensation reaction between the ethoxysilane or silanol groups of PEOS and the surface silanol groups of silica nanoparticles, PEOS acts as a binder for the silica nanoparticles at the interface. The $\mathrm{pH}$ of the medium was set between 1 and 4 for PEOS to act as an interfacial linker of silica particles. An optimal PEOS concentration was required for the formation of capsules. At high PEOS concentrations, the emulsion broke probably due to the destructive effect of the reaction product (ethanol) on emulsion stability, while lower PEOS concentrations were not sufficient to build a mechanically stable shell. Excess silica nanoparticles in the continuous phase of the emulsion led to the formation of a capsule shell composed of a well-defined particle bilayer bound with a sandwiched thin silica film (Figure 2(i)). Otherwise, a monolayer of silica nanoparticles was present at the interface. Dye release experiments were carried out. Two 
water-soluble dyes (Ru(bpy) and sulforhodamine B sodium salt) were tested and no fluorescence was detected in the external medium even after 30 days, implying that these capsules are impermeable. These capsules could be used to encapsulate highly aggressive fluids such as aqueous hydrogen peroxide due to the high thermal stability and chemical resistance of silica. Due to their brittleness, the encapsulated ingredient could only be released by applying mechanical force however.

Zhao et al. [44] prepared an o/w emulsion by emulsifying an oil containing PEOS into water. Various oils (toluene, hexadecane and hexyl acetate) were tested and partially hydrophobic silica nanoparticles were employed as the particle emulsifier dispersed in the aqueous phase. The resulting emulsion was stirred for 1 day at room temperature so that the sol-gel reaction occurred. By increasing the amount of silica particles, the diameter of the obtained capsules decreased up to a limit. By increasing the particle concentration the shell structure was not affected however, i.e. a particle monolayer was observed in all cases (Figure 2(j)). The effect of $\mathrm{pH}$ was also investigated; $\mathrm{pH}=9$ was optimal for PEOS to act as an effective glue for silica particles. From thermogravimetric analysis, the encapsulation efficiency was found to be close to $100 \%$ and the encapsulated hexadecane showed a slower evaporation rate than the nonencapsulated one. The release of oil occurred almost linearly in isothermal conditions and the release was faster at higher temperatures.

In the two cases presented above, to release the capsule's contents a mechanical force is required to break the shell, unlike the systems reported in refs. 45 and 46. Jiang et al. [45] prepared a w/o emulsion stabilised by silica nanoparticles of various diameters hydrophobised with dichlorodimethysilane. The two immiscible phases were an aqueous ammonia solution and toluene. After emulsification, TEOS silica precursor was added into the continuous phase and the emulsion was stirred for $20 \mathrm{~h}$. Since TEOS is hardly soluble in water, it undergoes hydrolysis and condensation at the water-toluene interface catalysed by ammonia and subsequently forms a silica layer to glue the silica particles at the interface (Figure 2(k)). The diameter of the obtained capsules depended on the diameter of the silica particles used to prepare the emulsions and capsules with a diameter between 200 and $500 \mathrm{~nm}$ were produced with $50 \mathrm{~nm}$ silica nanoparticles. The shell thickness increased by increasing the amount of TEOS. Dye release experiments were carried out by encapsulating methylene blue (MB). Interestingly is was found that ethanol triggered the release of MB from the silica capsules even from those containing the thickest shells. It was suggested that the wettability of hydrophobic silica particles with the aqueous phase might be an important factor influencing the release 
performance. MB molecules can pass through the pores within the silica shell but they remain accumulated here as the hydrophobic silica particles do not allow the water to wet the surface or penetrate in the silica shell structure. Therefore, the poor water spreading caused a very slow release. The presence of ethanol improved the wettability of the particles to the aqueous phase and hence enhanced the release of MB molecules (Figure 5(a)). Addition of nonionic surfactant had the same effect as adding ethanol. The ethanol-triggered release properties could be potentially applied to treat acute alcohol intoxication. Metadoxine drug could be encapsulated into the silica capsule and the ingested large amounts of alcohol in the stomach may trigger the release of the drug. Consequently the alcohol concentration in blood may be reduced by the accelerated metabolic degradation of ethanol.

Li et al. [46] stabilised a water-dodecane interface with partially hydrophobic silica nanoparticles rendering a w/o emulsion. Afterwards, oil-soluble tetramethoxysilane (TMOS) was added to the pre-formed Pickering emulsion to cross-link the particles. A pH-responsive copolymer was then covalently grafted to the cross-linked inorganic membrane. Two watersoluble dyes (calcein and rhodamine 6G) were successfully encapsulated within the colloidosomes as shown from florescence microscopy images. The transfer of the cross-linked colloidosomes (without copolymer covalently grafted) into water resulted in release of dye molecules into the continuous phase independent of the $\mathrm{pH}$. However, when dye molecules were encapsulated within cross-linked copolymer-functionalised colloidosomes, the release was $\mathrm{pH}$-dependent. They were retained at neutral $\mathrm{pH}$ but released under acidic (calcein) or alkaline (rhodamine 6G) conditions. Similar experiments were conducted by encapsulating charged proteins such as cytochrome c, ferritin and myoglobin. An enzyme-catalysed reaction was also carried out. Alkaline phosphatase (ALP) was encapsulated in the w/o Pickering emulsion. After cross-linking with TMOS and copolymer modification of the silica nanoparticle shell, the colloidosomes were transferred into water. 4-nitrophenyl phosphate was then added to the continuous aqueous phase and the kinetics of formation of 4-nitrophenolate was monitored at different $\mathrm{pH}$. For the cross-linked copolymer-modified colloidosomes the highest enzymatic activity occurred at $\mathrm{pH} 9.1$ while for the cross-linked colloidosomes (without copolymer) the reaction rates increased by increasing the $\mathrm{pH}$ from 8.4 to 9.8. The rates were much faster in bulk solution compared to those in colloidosomes (Figure 5(b)). This suggests that the cross-linked silica nanoparticle membrane acts as a considerable diffusion barrier.

Up until now, all the emulsions converted to capsules with a silica precursor included in this section were stabilised by silica particles, producing an all-silica shell. Zhan et al. [47] however 
stabilised a w/o emulsion of an acidic water phase and toluene containing tetraethyl orthosilicate (TEOS) or tetrabutyl orthosilicate (TBOS) with cinnamate-grafted cellulose nanocrystals (Cin-CNC) as the particulate emulsifier. After homogenisation, the emulsion was kept for several days to allow the cross-linking of TEOS or TBOS precursors. TEOS is not soluble in water but is expected to hydrolyse and condense at the water-toluene interface to form an intricate network of polysiloxane within the Cin-CNC shell. Rhodamine B or fluorescent DNA were encapsulated by dissolving them in water prior to emulsification. No fluorescence was detected in the external medium after 1 month. This indicates that the structure of the Cin-CNC/silica shell was sufficiently compact to ensure long-term retention of such molecules. A timely release of the encapsulated compounds was accomplished by breaking the thin shell under mechanical force.

\section{(f) Interfacial polymerisation}

The method of interfacial polymerisation was previously introduced for the preparation of empty capsules. Likewise, interfacial polymerisation methods for the preparation of liquidfilled capsules are divided into those where the components are split between the two immiscible phases ensuring polymerisation occurs at the interface (polyurethane and polyurea) and those where the components originate in the same phase.

Yi et al. [48] first prepared an o/w emulsion of an aqueous solution containing lignin particles with an oil phase containing a mixture of IPDI and diphenyl methane diisocyanate (MDI). As MDI is more reactive than IPDI, isocyanate groups in MDI react promptly with hydroxyl groups of lignin or water at the interface of emulsion droplets to form a thin polyurethane membrane. The morphology of the Pickering emulsion was studied by varying the IPDI-MDI volume ratio in the oil phase. By increasing the amount of MDI, oil droplets had a less spherical shape. Microcapsules are then formed by in situ interfacial polymerisation of a melamine formaldehyde pre-polymer (pre-MF). The o/w emulsion was added dropwise to an aqueous solution containing pre-MF and PVA and the reaction was conducted for $2 \mathrm{~h}$. Pre-MF selfcrosslinks to form an MF polymer which wraps around the emulsion droplets. Pre-MF can also react with diisocyanate within the oil phase to generate polyurea. Therefore, the capsules contain three shells: polyurethane, polyurea and melamine-formaldehyde polymer. These microcapsules showed remarkable anti-corrosive behaviour. Microcapsules containing selfhealing agents were dispersed into epoxy resin to prepare the self-healing coatings, followed by mixing hardener into the composites. The prepared self-healing composites were applied to 
steel plates and cured at room temperature for $24 \mathrm{~h}$. After curing, the self-healing coatings and control samples were scratched with a scalpel and all specimens were immersed in $\mathrm{NaCl}$ solution. After $120 \mathrm{~h}$ of submersion, the scratched regions of the control samples were severely corroded while those containing the self-coating did not show any surface damage.

Another example of capsules as a self-healing coating is that given by $\mathrm{Li}$ et al. [49]. They prepared microcapsules containing isocyanate via thiol-ene photopolymerisation in a Pickering emulsion. Hydrolyzed poly(glycidyl methacrylate), PGMA particles were selected as the particulate emulsifier to form an o/w emulsion. The oil phase contained 1,3,5-tri-2-propenyl1,3,5-triazine-2,4,6 (1H, 3H, 5H)-trione (TTT), IPDI and trimethylolpropane tris (3mercaptopropionate) (TMMP) while the water phase was an aqueous suspension of hydrolysed PGMA particles with a photoinitiator. Under UV irradiation, TTT and TMMP polymerised and a polythioether network formed at the interface creating the microcapsule shell (Figure 2(1)). A glass substrate was then coated with acrylate embedding IPDI-loaded microcapsules. The surface was damaged and the substrate was immersed in water for $72 \mathrm{~h}$. Self-healing could be achieved from the reaction of IPDI released from the capsules and water.

Unlike the other compositions reported in this review, Lu et al. [50] prepared capsules from a non-aqueous solvent-in-oil emulsion. Diethylenetriamine (DETA) containing other polyamines was used as the polar solvent while a mixture of decalin and hexadecane (DH) was used as the non-polar phase. As DETA is partially miscible with the oil mixture, guanidinium chloride $(\mathrm{GuHCl})$ was added to prevent DETA from dissolving in the hydrocarbon phase. Polyisobutylene (PIB) was added to the continuous phase as a viscosity modifier. Hydrophobically functionalised clay particles were used to prepare a DETA-in-DH Pickering emulsion. Once the stable emulsion was prepared, an isocyanate was added to the continuous phase. A polyurea shell was then formed via an interfacial polycondensation reaction between the isocyanate in oil and amine on the surface of the emulsion droplets. Capsules in epoxy resin containing salicylaldehyde were chemically stable as the polyurea shell prevented direct contact between the two phases. After capsule rupture, a fast reaction between salicylaldehyde and the capsule contents occurred.

By contrast, Luo et al. [51] prepared capsules with ionic liquids (IL). They first prepared emulsions (either IL/w or IL/o) using graphene oxide nanosheets (GO) or octadecylaminefunctionalized GO $\left(\mathrm{C}_{18}-\mathrm{GO}\right)$, respectively. For the IL/w case, an ionic liquid containing 1,6diisocyanatohexane (HDI) was emulsified into an aqueous $\mathrm{Na}_{2} \mathrm{CO}_{3}$ suspension containing GO. 
Afterwards, an aqueous solution containing 1,6-hexanediamine (HMDA) was added dropwise to the previously formed emulsion and the vial was swirled by hand. The mixture was left unagitated for $72 \mathrm{~h}$ before addition of water and aqueous ammonium hydroxide, then left unagitated for $5 \mathrm{~h}$ to quench unreacted isocyanate groups. Solid particles were collected by filtration, washed and dried under vacuum. For the preparation of IL/o emulsions, a mixture containing the ionic liquid and ethylenediamine (EDA) was homogenised with octane containing $\mathrm{C}_{18}-\mathrm{GO}$. Afterwards, a solution of HDI in octane was added dropwise to the emulsion. Therefore, with both procedures, a polymer (polyurea) was formed at the liquidliquid interface upon interfacial polymerisation. The size of the microcapsules depended on the monomer and the ionic liquid used but was around $40 \mu \mathrm{m}$. It was shown that these capsules could be used as an active column material for the extraction of phenol from oil. A standard solution of phenol in hexane was passed through a column packed with either capsules containing an ionic liquid or the same capsules after extraction of IL. The column eluent was characterised by UV-vis absorption spectroscopy and the concentration of phenol was determined. The shell is not porous but is permeable to phenol. As shown in Figure 5(c), the encapsulated ionic liquid and not the composite shell is responsible for the majority of the phenol removal, with more than $98 \%$ of phenol extracted from the medium after passing 12 $\mathrm{mL}$ of a phenol solution.

In a previous publication of the same group, Luo et al. [52] used a similar system to produce capsules from IL/w emulsions followed by polymerisation as explained above. An aqueous $\mathrm{Na}_{2} \mathrm{CO}_{3}$ solution containing $\mathrm{GO}$ nanosheets (GO) was mixed with a second phase containing ionic liquid and hexamethylene diisocyanate. Afterwards, a hexamethylenediamine aqueous solution was added dropwise to the emulsion and the mixture was gently swirled by hand. The mixture was left unagitated for $72 \mathrm{~h}$, followed by addition of ammonium hydroxide to remove unreacted isocyanate functional groups. The resulting capsules of IL in a shell of polyurea/GO nanosheets were collected by filtration, washed, dried and thermally reduced at $200{ }^{\circ} \mathrm{C}$ to render the GO nanosheets electrically conductive (rGO). These capsules could find application in electrical double-layer capacitors (EDLCs). EDLCs store energy electrostatically on the surface of the active material and use electrolyte counterions to balance the charge on the electrode. Traditional electrolyte solutions are aqueous or organic. However, they have either small operating voltages (aqueous) or poor thermal stability and solvent flammability (organic). Ionic liquids have large operating voltages and good thermal stability, making them good candidates for the new generation of EDLCs. The electrochemical performance of the IL- 
containing polyurea/rGO capsules was evaluated and compared to both the commercial porous carbon material YP-50 and polyurea/GO capsule shells after removal of IL. Figure 5(d) shows the specific capacitance determined by cyclic voltammetry of these three systems at two temperatures $\left(18\right.$ and $\left.60^{\circ} \mathrm{C}\right)$ versus the scan rate. The capacitance of IL-containing capsules at low temperature is higher than that of the other two systems. These results suggest that these composite capsules can enhance the performance of EDLCs.

Dardelle et al. [53] utilised polymerisation to prepare capsules from emulsions stabilised by coacervate droplets (deformable particles) formed upon the electrostatic interaction of oppositely charged polyelectrolytes. In this liquid-liquid type of phase separation, which occurs when the interaction between the two polyelectrolytes is weak, liquid droplets concentrated in the two polymers are dispersed within an aqueous continuous phase. The use of coacervate droplets from synthetic non-surface-active polyelectrolytes to stabilise o/w emulsions was reported recently [54]. In ref. 53, gelatin and acacia gum were used as the positively charged protein and the polyanion, respectively. The aqueous phase containing the coacervate droplets was emulsified with an oil phase containing an aliphatic oligoisocyanate. The polymer-rich coacervate droplets spontaneously deposit at the oil-water interface, thereby encapsulating the oil drops. Transglutaminase was then added as a cross-linker. Amine monomers were subsequently added to the aqueous continuous phase and interfacial polymerisation was induced from the interaction of the amine monomers and the isocyanate molecules to form a polyurea membrane. An important application of the composite capsules described here is to provide a delivery vehicle for volatile fragrance oil molecules in consumer products, e.g. under harsh conditions in the presence of surfactant. The resistance of the composite capsules against leakage of the encapsulated molecules was assessed in a model solution of sodium dodecyl sulfate. The composite capsules containing coacervates and polyurea are more stable against the loss of encapsulated oil into the surfactant solution compared to the coacervate-only capsules. The behaviour of the capsules as delivery systems for encapsulated fragrance oils was evaluated using human sensory panel tests. The panellists rated the perceived olfactive intensity of a detergent solution before usage and after lathering for $10 \mathrm{~s}$ with warm water. In the case of the composite capsules, the perceived olfactive intensity was weak before rubbing but became strong after lathering.

$\mathrm{Wu}$ et al. [55] prepared hybrid microcapsules for the encapsulation of volatile bioactive compounds. An o/w Pickering emulsion was first prepared with a mixture of silica nanoparticles of different wettability. The oil droplets contained a mixture of five volatile 
fragrance compounds and an isocyanate. By increasing the temperature to $70{ }^{\circ} \mathrm{C}$, interfacial reactions between the isocyanates in oil and the amino or hydroxyl groups on the surface of silica particles occurred leading to the formation of a polymeric shell locking the particles. Thermogravimetric tests confirmed the low permeability of the capsules compared to the Pickering emulsion without shell reinforcement.

A different example for the preparation of capsules via polymerisation is that given by Yin et al. [56]. In this case polymerisation occurs with all the components in the oil phase followed by a sintering process. Poly(glycidyl methacrylate), PGMA particles were used as the particle stabiliser for the two-phase system composed of an aqueous particle dispersion and a mixture of styrene, DVB and AIBN as the oil phase. The diameter of these particles is considerably larger compared to the others included in this review and were $1.1 \mu \mathrm{m}$. An o/w emulsion was obtained. Afterwards, $\mathrm{NaNO}_{2}$ was added to the emulsion to inhibit radical polymerisation in the aqueous phase. Polymerisation was carried out at $60{ }^{\circ} \mathrm{C}$ for $16 \mathrm{~h}$. During polymerisation in the oil phase of Pickering emulsion droplets, polystyrene chains precipitated at the interface of the droplets. PGMA particles and the polystyrene shell adhere to one another but are easily detached, which deteriorates the tightness of the microcapsules. To improve this, PGMA and polystyrene were thermally sintered into an integral shell at $105{ }^{\circ} \mathrm{C}$. Sintering significantly improved the durability and the thermal stability of the microcapsules so they could find a potential application as phase change material composites for thermal energy storage and temperature regulation.

Another example of polymerisation initiated in the oil phase is that given by Huo et al. [57]. In this case, the oil phase was composed of styrene, DVB, an initiator and either dodecane, toluene or heptane. The aqueous phase contained metal organic framework particles (MOF) dispersed in water as particulate stabiliser. An o/w emulsion was obtained which was subsequently polymerised leaving a polymer layer at the oil-water interface (Figure 2(m)). The thickness of the polymer shell depended on the amount of styrene and DVB present in oil. A dye (oil red $\mathrm{O}$ ) was successfully encapsulated. Capsules were re-dispersed in ethanol to assess the dye release by UV-vis spectroscopy. Only $9.7 \%$ of the encapsulated dye was released after $12 \mathrm{~h}$ (Figure 5(e)). Moreover, addition of acid dissolves the MOF particles and the dye is released rapidly through the polymer shell, which appears to be highly permeable to the dye.

Using an oil phase similar to that in ref. 57, Popadyuk et al. [58] prepared an o/w emulsion with an aqueous phase containing peroxidized latex particles as emulsifier. Peroxidized latex 
particles were obtained by polymerisation and contained carboxyl and peroxide functional groups on their surface. Emulsions stable to different extents were obtained between $\mathrm{pH} 3$ and 9. The o/w emulsion so-obtained was polymerised at $80{ }^{\circ} \mathrm{C}$ for $24 \mathrm{~h}$ producing a polymer layer at the inner droplet interface. Capsules of different dimensions and morphological characteristics were obtained by varying the oil phase composition and $\mathrm{pH}$ of the aqueous phase.

Finally, Tang et al. [59] provide another example of the formation of microcapsules where interfacial polymerisation plays a crucial role in shell rigidification. In this case, an o/w emulsion stabilised with cinnamoyl chloride-modified cellulose nanocrystals dispersed in water was first prepared. The aqueous dispersion was homogenised with an oil phase containing oil of turpentine, 2,4-dichlorophenoxyacetic acid (2,4-D) and butanol. 2,4 D is a model herbicide and butanol is chosen as the adjuvant solvent due to its high solubility for 2,4$\mathrm{D}$ and low toxicity. Capsules were prepared by deposition of polydopamine on the Pickering emulsion template by oxidative self-polymerisation of dopamine in water. The shell thickness increased with the amount of dopamine used. Polydopamine capsules containing 2,4-D were dispersed in ethanol and left shaking at room temperature for $48 \mathrm{~h}$. The dispersion was then filtered, collected and subjected to UV-vis analysis to measure the amount of 2,4-D released into the medium (Figure 5(f)). The encapsulation efficiency increased with dopamine content up to $90 \%$. The release behaviour was also investigated by varying the solvent medium and it was found that the release rate decreased by decreasing the ethanol content. Moreover all capsules displayed sustained release behaviour, with those containing a thinner polymer shell exhibiting a faster release rate.

\section{(g) Interfacial reaction}

Panhuis and Paunov [60] used glutaraldehyde as a cross-linker to rigidize the shell of a w/o emulsion between an aqueous phase containing isopropanol and tricaprilyn stabilised with amine-functionalised multi-walled carbon nanotubes. Aldehydes react with primary amines resulting in imines. This reaction was used to cross-link the self-assembled carbon nanotube shell. Duncan et al. [61] prepared capsules for the treatment of bacterial biofilms. Bacterial biofilms are highly resilient microbial assemblies that are difficult to eradicate. Phytochemicals (essential oils) have emerged as a promising alternative to traditional antimicrobials to treat antibiotic-resistant bacteria. The generally poor aqueous solubility and stability of these oils requires them to be encapsulated however. A primary o/w emulsion was stabilised with cationic amine-functionalised silica nanoparticles. The oil phase was cinnamaldehyde dissolved in 
peppermint oil. The surface amines on the nanoparticles react with cinnamaldehyde in oil to form an imine. It was shown that the microcapsules can penetrate into biofilms and kill bacterial cells. In addition, the acidic $\mathrm{pH}$ of the biofilm environment should promote the hydrolysis of the imines enhancing the sustained release of cinnamaldehyde.

\section{(h) Electrostatic interaction}

Interestingly, sub-micron colloidosomes were prepared by Li et al. [62] by electrostatic assembly of organosilica nanoparticles of opposite charge. Silica particles at $\mathrm{pH}=7$ are negatively charged. By doping the particles with different amounts of a positively charged nitrophenylene-ammonium-bridged alkoxysilane (NB), silica particles of opposite charge could be prepared. An aqueous phase containing both kinds of particles at $\mathrm{pH}=8$ was mixed with toluene to form an o/w emulsion by sonication. The emulsion was then stirred for 1 hour to stabilise the system without additional covalent cross-linking. Colloidosomes $(d=200-700$ $\mathrm{nm}$ ) were then collected by centrifugation. Upon UV irradiation, the photoreaction of the NB moieties within positively charged particles induced a charge reversal and the concomitant disassembly of the colloidosomes due to electrostatic repulsion. To probe the use of these colloidosomes as nanocarriers for the release of actives, Nile red was encapsulated by dissolving it in toluene. The dispersion was irradiated for periods of $5 \mathrm{~min}$ with UV light and the laser was off for $5 \mathrm{~min}$ before the sample was irradiated again. The release of the dye was monitored by UV/Vis spectroscopy and plotted as a function of time. Before irradiation, the dye was not released from the colloidosome nanocarrier. However, when the light was on for 5 min, colloidosomes became unstable releasing $60 \%$ of Nile red. Upon a total irradiation time of $10 \mathrm{~min}$, up to $80 \%$ of the encapsulated dye could be released.

\section{Conclusions and prospect}

This brief review describes some traditional and more recent approaches used to prepare either empty or liquid-filled capsules from Pickering emulsion templates. It is a growing field with much more to accomplish before commercial realisation. Once the Pickering emulsion is prepared, the particle layer must be reinforced which can be achieved through interfacial polymerisation or crystallisation, the use of a sacrificial template, deposition of polymer layers, gelation, cross-linking or addition of a silica precursor amongst others. Applications of these colloidal capsules include drug or dye encapsulation and subsequent release, in wastewater treatment, as catalysts and even an exotic use as an electrochemical capacitor. In the majority 
of cases though, the encapsulated ingredient cannot be retained in the capsule core for long periods of time as it diffuses through pores in the shell. Despite great improvements in this regard upon addition of a silica precursor, in order to release the encapsulated active the shell must broken with mechanical force which might not be convenient for certain applications.

In most of the examples cited, the liquids of the simple Pickering emulsion are oil and water. Only rare examples exist in which water is replaced by a polar solvent or either oil or water is replaced by an ionic liquid. Future work may concentrate on capsules prepared from particle-stabilised multiple emulsions (o/w/o and w/o/w) and those from water-free (oil-in-oil) and oil-free (water-in-water) emulsions. In addition, high throughput microfluidics offers the opportunity to enable the preparation of monodisperse capsules of interest for fundamental studies. The majority of capsules made to date are micron-sized; future work may be directed at capsules originating from nanoemulsions. This is more challenging due to the increased possibility of Ostwald ripening occurring in precursor emulsions but at least one report shows the use of nano-silica in stabilising such emulsions [63]. More effort should also be put into establishing the precise mechanism by which particle layers become reinforced. Some of the arguments so far are speculative and concrete evidence is required. Finally, there has been very little theoretical work describing the diffusion of material into or out of such capsules to include the effects of capsule size, wall thickness, particle coverage in walls and pore size/number. This would guide the formulation scientist in designing the optimum capsule for the appropriate need.

\section{Acknowledgements}

The authors kindly acknowledge funding by the H2020FETOPEN-2016-2017 program of the European Commission (Grant agreement number: 737266-ONE FLOW). 


\section{References}

[1] M. Vert, Y. Doi, K.-H. Hellwich, M. Hess, P. Hodge, P. Kubisa, M. Rinaudo and F. Schué, Terminology for biorelated polymers and applications (IUPAC Recommendations 2012), Pure Appl. Chem., 2012, 84, 377-410.

[2] B.F. Gibbs, S. Kermasha, I. Alli and C.N. Mulligan, Encapsulation in the food industry: a review, Int. J. Food Sci. Nutr., 1999, 50, 213-224.

[3] A. Kumari, R. Singla, A. Guliani and S.K. Yadav, Nanoencapsulation for drug delivery, EXCLI J., 2014, 13, 265-286.

[4] F. Casanova and L. Santos, Encapsulation of cosmetic active ingredients for topical application - a review, J. Microencapsul., 2016, 33, 1-17.

[5] J. Ruiz Canizales, G.R. Velderrain Rodríguez, J.A. Domínguez Avila, A.M. Preciado Saldaña, E. Alvarez Parrilla, M.A. Villegas Ochoa and G.A. González Aguilar, in Bioactive Molecules in Food, ed. J.M. Mérillon and K.G. Ramawat, Springer, Heidelberg, 2018.

[6] U.R. Pothakamury and G.V. Barbosa-Cánovas, Fundamental aspects of controlled release in foods, Trends Food Sci. Technol., 1995, 6, 397-406.

[7] K.C. Bentz and D.A. Savin, Hollow polymer nanocapsules: synthesis, properties, and applications, Polym. Chem., 2018, 9, 2059-2081.

[8] L. He, J. Hu and W. Deng, Preparation and application of flavour and fragrance capsules. Polym. Chem., 2018, 9, 4926-4946.

[9] I. Dragostin, O. Dragostin, A.-M. Pelin, C. Grigore and C.L. Zamfir, The importance of polymers for encapsulation process and for enhanced cellular functions, J. Macromol. Sci., Part A: Pure Appl. Chem., 2017, 54, 489-493.

[10] H.N. Yow and A.F. Routh, Formation of liquid core-polymer shell microcapsules, Soft Matter, 2006, 2, 940-949.

[11] O.D. Velev, K. Furusawa and K. Nagayama, Assembly of latex particles by using emulsion droplets as templates. 1. Microstructured hollow spheres, Langmuir, 1996, 12, 2374 2384.

[12] O.D. Velev, K. Furusawa and K. Nagayama, Assembly of latex particles by using emulsion droplets as templates. 2. Ball-like and composite aggregates, Langmuir, 1996, 12, 2385-2391.

[13] A.D. Dinsmore, M.F. Hsu, M.G. Nikolaides, M. Marquez, A.R. Bausch and D.A. Weitz, Colloidosomes: selectively permeable capsules composed of colloidal particles, Science, 2002, 298, 1006-1009.

[14] K.L. Thompson, M. Williams and S.A. Armes, Colloidosomes: synthesis, properties and applications, J. Colloid Interface Sci., 2015, 447, 217-228.

[15] H. Zhu, L. Lei, B.-G. Li and S. Zhu, Development of novel materials from polymerisation of Pickering emulsion templates, Adv. Polym. Sci., 2017, 280, 101-119.

[16] T. Bollhorst, K. Rezwan and M. Maas, Colloidal capsules: nano- and microcapsules with colloidal particle shells, Chem. Soc. Rev., 2017, 46, 2091-2126.

[17] S.A.F. Bon, Pickering emulsion polymerisation in Encyclopedia of Polymeric Nanomaterials, eds. S. Kobayashi and K. Müllen, Vol. 2, 2015, Springer-Verlag, Berlin, p. 264. 
[18] K. Zhang, Q. Wang, H. Meng, M. Wang, W. Wu and J. Chen, Preparation of polyacrylamide/silica composite capsules by inverse Pickering emulsion polymerization, Particuology, 2014, 14, 12-18.

[19] S. Arditty, C.P. Whitby, B.P. Binks, V. Schmitt and F. Leal-Calderon, Some general features of limited coalescence in solid-stabilized emulsions, Eur. Phys. J. E, 2003, 11, $273-$ 281.

[20] T. Chen, P.J. Colver and S.A.F. Bon, Organic-inorganic hybrid hollow spheres prepared from $\mathrm{TiO}_{2}$-stabilized Pickering emulsion polymerisation, Adv. Mater., 2007, 19, 2286-2289.

[21] S.A.F. Bon, S. Cauvin and P.J. Colver, Colloidosomes as micron-sized polymerisation vessels to create supracolloidal interpenetrating polymer network reinforced capsules, Soft Matter, 2007, 3, 194-199.

[22] W. Chen, X. Liu, Y. Liu and H. Kim, Synthesis of microcapsules with polystyrene/ZnO hybrid shell by Pickering emulsion polymerisation, Colloid Polym. Sci., 2010, 288, 1393-1399.

[23] K. Zhang, W. Wu, K. Guo, J.-F. Chen and P.-Y. Zhang, Magnetic polymer enhanced hybrid capsules prepared from a novel Pickering emulsion polymerisation and their application in controlled drug release, Colloids Surf. A, 2009, 349, 110-116.

[24] Y. Yang, Y. Ning, C. Wang and Z. Tong, Capsule clusters fabricated by polymerization based on capsule-in-water-in-oil Pickering emulsions, Polym. Chem., 2013, 4, 5407-5415.

[25] X. Wang, L. Chen, G. Sun and R. Liu, Hollow microcapsules with controlled mechanical properties templated from Pickering emulsion droplets, Macromol. Chem. Phys., 2019, 220, $1800395-1800399$.

[26] W. Huo, X. Zhang, K. Gan, H. Li, S. Yan, Y. Chen and J. Yang, Ceramic particlestabilized foams/emulsions with UV light response and further synthesis of ceramic capsules, Chem. Eng. J., 2019, 360, 1459-1467.

[27*] G. Zhang and C. Wang, Pickering emulsion-based marbles for cellular capsules, Materials, 2016, 9, 572.

Preparation of hollow capsules after evaporation of oil and water from oil liquid marbles containing water droplets. Both interfaces are stabilised by the same silica particles.

[28] H. Strohm and P. Löbmann, Porous $\mathrm{TiO}_{2}$ hollow spheres by liquid phase deposition on polystyrene latex-stabilised Pickering emulsions, J. Mater. Chem., 2004, 14, 2667-2673.

[29**] J. Xu, A. Ma, Z. Xu, X. Liu, D. Chu and H. Xu, Synthesis of Au and Pt hollow capsules with single holes via Pickering emulsion strategy, J. Phys. Chem. C, 2015, 119, 28055-28060.

Describes the formation of $\mathrm{Au}$ and $\mathrm{Pt}$ hollow open-mouthed nanocapsules from a galvanic reaction that takes place at the surface of $\mathrm{Cu}_{2} \mathrm{O}$ nanoparticles used as the Pickering stabiliser. These displayed higher catalytic activity compared with closed hollow capsules.

[30**] D. Lee and D.A. Weitz, Nonspherical colloidosomes with multiple compartments from double emulsions, Small, 2009, 5, 1932-1935. 
Microcapsules with non-spherical shapes prepared using microfluidics and multiple w/o/w emulsion template. The capsule shape can be controlled by varying the number of inner water droplets.

[31**] W. Wang, A.H. Milani, Z. Cui, M. Zhu and B.R. Saunders, Pickering emulsions stabilized by $\mathrm{pH}$-responsive microgels and their scalable transformation to robust submicrometer colloidosomes with selective permeability, Langmuir, 2017, 33, 8192-8200.

Sub-micron capsules prepared using $\mathrm{pH}$-responsive microgel particles that self-crosslink upon heating. The pore size and hence the shell permeability can be controlled by changing the $\mathrm{pH}$.

[32] P.A. Demina, D.O. Grigoriev, G.M. Kuz'micheva and T.V. Bukreeva, Preparation of Pickering-emulsion-based capsules with shells composed of titanium dioxide nanoparticles and polyelectrolyte layers, Colloid J., 2017, 79, 142-148.

[33] J. Li and H.D.H. Stöver, Pickering emulsion templated layer-by-layer assembly for making microcapsules, Langmuir, 2010, 16, 15554-15560.

[34] Z. Ao, Z. Yang, J. Wang, G. Zhang and T. Ngai, Emulsion-templated liquid core-polymer shell microcapsule formation, Langmuir, 2009, 25, 2572-2574.

[35] G.M. Radulova, T.G. Slavova, P.A. Kralchevsky, E.S. Basheva, K.G. Marinova and K.D. Danov, Encapsulation of oils and fragrances by core-in-shell structures from silica particles, polymers and surfactants: The brick-and-mortar concept, Colloids Surf. A, 2018, 559, 351-364.

[36**] X. Wang, W. Zhou, J. Cao, W. Liu and S. Zhu, Preparation of core-shell $\mathrm{CaCO}_{3}$ capsules via Pickering emulsion templates, J. Colloid Interface Sci., 2012, 372, 24-31.

Food-grade $\mathrm{CaCO}_{3}$ microparticles act as the stabiliser of an o/w emulsion and as nucleation sites for subsequent crystallisation of $\mathrm{CaCO}_{3}$ forming the capsule shell. Triggered release of the capsule content is achieved upon dissolution of the $\mathrm{CaCO}_{3}$ shell in acid.

[37] P.F. Noble, O.J. Cayre, R.G. Alargova, O.D. Velev and V.N. Paunov, Fabrication of "hairy" colloidosomes with shells of polymeric microrods, J. Am. Chem. Soc., 2004, 162, 8092-8093.

[38] J.-Y. Leong, B-T. Tey, C-P. Tan and E.-S. Chan, Nozzleless fabrication of oil-core biopolymeric microcapsules by the interfacial gelation of Pickering emulsion templates, ACS Appl. Mater. Interfaces, 2015, 7, 16169-16176.

[39*] M. Marquis, V. Alix, I. Capron, S. Cuenot and A. Zykwinska, Microfluidic encapsulation of Pickering oil microdroplets into alginate microgels for lipophilic compound delivery, ACS Biomater. Sci. Eng., 2016, 2, 535-543.

Alginate gelation with $\mathrm{Ca}^{2+}$ of aqueous globules containing multiple oil droplets stabilised by cellulose nanocrystals prepared in a microfluidic device.

[40] W.W. Mwangi, K-W. Ho, C-W. Ooi, B-T. Tey and E-S. Chan, Facile method for forming ionically cross-linked chitosan microcapsules from Pickering emulsion templates, Food Hydrocolloids, 2016, 55, 26-33.

[41] A. San Miguel, J. Scrimgeour, J.E. Curtis and S.H. Behrens, Smart colloidosomes with a dissolution trigger, Soft Matter, 2010, 6, 3163-3166. 
[42] S. Zhou, J. Fan, S.S. Datta, M. Guo, X. Guo and D.A. Weitz, Thermally switched release from nanoparticle colloidosomes, Adv. Funct. Mater., 2013, 23, 5925-5929.

[43] H.L. Wang, X.M. Zhu, L. Tsarkova, A. Pich and M. Möller, All-silica colloidosomes with a particle-bilayer shell, ACS Nano, 2011, 5, 3937-3942.

[44] Y. Zhao, Y. Li, D.E. Demco, X. Zhu and M. Möller, Microencapsulation of hydrophobic liquids in closed all-silica colloidosomes, Langmuir, 2014, 30, 4253-4261.

[45*] H. Jiang, L. Hong, Y. Li and T. Ngai, All-silica submicrometer colloidosomes for cargo protection and tunable release, Angew. Chem. Int. Ed., 2018, 57, 11662-11666.

Preparation of nanocapsules through hydrolysis and condensation reactions of a silica precursor (TEOS) at the oil-water interface. Release of encapsulated cargo achieved by adding ethanol or surfactant.

[46] M. Li, R.L. Harbron, J.V.M. Weaver, B.P. Binks and S. Mann, Electrostatically gated membrane permeability in inorganic protocells, Nat. Chem., 2013, 5, 529-536.

[47] Z. Zhang, K.C. Tam, X. Wang and G. Sèbe, Inverse Pickering emulsions stabilized by cinnamate modified cellulose nanocrystals as templates to prepare silica colloidosomes, ACS Sustainable Chem. Eng., 2018, 6, 2583-2590.

[48] H. Yi, Y. Yang, X. Gu, J. Huang and C. Wang, Multilayer composite microcapsules synthesized by Pickering emulsion templates and their application in self-healing coating, $J$. Mater. Chem. A, 2015, 3, 13749-13757.

[49*] C. Li, J. Tan, J. Gu, L. Qiao, B. Zhang and Q. Zhang, Rapid and efficient synthesis of isocyanate microcapsules via thiol-ene photopolymerisation in Pickering emulsion and its application in self-healing coating, Compos. Sci. Technol., 2016, 123, 250-258.

Microcapsules obtained from a Pickering emulsion stabilised by hydrolysed poly(glycidyl methacrylate) particles followed by thiol-ene polymerisation with UV light. Interesting use of capsules as a self-healing coating.

[50] X. Lu, J.S. Katz, A.K. Schmitt and J.S. Moore, A robust oil-in-oil emulsion for the nanoaqueous encapsulation of hydrophilic payloads, J. Am. Chem. Soc., 2018, 140, 3619-3625.

[51] Q. Luo, Y. Wang, Z. Chen, P. Wei, E. Yoo and E. Pentzer, Pickering emulsion-templated encapsulation of ionic liquids for contaminant removal, ACS Appl. Mater. Interfaces, 2019, 11, 9612-9620.

[52**] Q. Luo, P. Wei, Q. Huang, B. Gurkan and E. Pentzer, Carbon capsules of ionic liquid for enhanced performance of electrochemical double-layer capacitors, ACS Appl. Mater. Interfaces, 2018, 10, 16707-16714.

Encapsulation of ionic liquids in a shell of polyurea and conducting graphene oxide nanosheets demonstrates a new approach in preparing electrochemical double-layer capacitor electrode materials.

[53] G. Dardelle, M. Jacquemond and P. Erni, Delivery systems for low molecular weight payloads: core/shell capsules with composite coacervate/polyurea membranes, Adv Mater., 2017, 29, 1606099-1606104. 
[54] A.M. Bago Rodriguez, B.P. Binks and T. Sekine, Emulsion stabilization by complexes of oppositely charged synthetic polyelectrolytes, Soft Matter, 2018, 14, 239-254.

[55] Y. Wu, J. Shen, V. Larcinese-Hafner, P. Erni and L. Ouali, Hybrid microcapsules with tunable properties via Pickering emulsion templates for the encapsulation of bioactive volatiles, RSC Adv., 2016, 6, 102595-102602.

[56] D. Yin, L. Bai, Y. Jia, J. Liu and Q. Zhang, Microencapsulation through thermally sintering Pickering emulsion-based colloidosomes, Soft Matter, 2017, 13, 3720-3725.

[57] J. Huo, M. Marcello, A. Garai and D. Bradshaw, MOF-Polymer composite microcapsules derived from Pickering emulsions, Adv. Mater., 2013, 25, 2717-2722.

[58] A. Popadyuk, N. Popadyuk, I. Tarnavchyk, S. Voronov and A. Voronov, Colloidosomes from peroxidized Pickering emulsions, Int. J. Theor. Appl. Nanotechol., 2015, 3, 20-27.

[59] C. Tang, Y. Li, J. Pun, A.S.M. Osman and K.C. Tam, Polydopamine microcapsules from cellulose nanocrystal stabilized Pickering emulsions for essential oil and pesticide encapsulation, Colloids Surf. A, 2019, 570, 403-413.

[60] M. Panhuis and V.N. Paunov, Assembling carbon nanotubosomes using an emulsioninversion technique, Chem. Commun., 2005, 13, 1726-1728.

[61] B. Duncan, X. Li, R.F. Landis, S. T. Kim, A. Gupta, L.-S. Wang, R. Ramanathan, R. Tang, J.A. Boerth and V.M. Rotello, Nanoparticle-stabilized capsules for the treatment of bacterial biofilms, ACS Nano, 2015, 9, 7775-7782.

[62*] S. Li, B.A. Moosa, J.G. Croissant and N.M. Khashab, Electrostatic assembly/disassembly of nanoscaled colloidosomes for light-triggered cargo release, Angew. Chem. Int. Ed., 2015, 54, $6804-6808$.

The nanocapsule shell consists of positively and negatively charged particles. Colloidosome disassembly is achieved through electrostatic repulsion by UV light as it induces charge reversal of positively charged particles.

[63] K.H. Persson, I.A. Blute, I.C. Mira and J. Gustafsson, Creation of well-defined particle stabilized oil-in-water nanoemulsions, Colloids Surf. A, 2014, 459, 48-57. 
Figure 1. Applications of hollow capsules from Pickering emulsion templates. (a) Absorption of $\mathrm{Hg}(\mathrm{II})$ ions from water as a function of contact time by $\mathrm{SiO}_{2}$ nanoparticles, PAM hydrogel and $\mathrm{PAM} / \mathrm{SiO}_{2}$ composite capsules. Reproduced from ref. 18 with permission from Elsevier, (b) photodegradation rates of dichloroacetic acid in toluene-leached $\mathrm{TiO}_{2}$ capsules prior to calcination (circles) and after calcination at $600{ }^{\circ} \mathrm{C}$ (stars), $400{ }^{\circ} \mathrm{C}$ (squares), $300{ }^{\circ} \mathrm{C}$ (triangles) and $200{ }^{\circ} \mathrm{C}$ (diamonds). Reproduced from ref. 28 with permission from The Royal Society of Chemistry, (c) reduction of 4-nitrophenol $\left(C_{t} / C_{0}\right)$ against reaction time $(t)$ catalysed by intact Au hollow capsules and open-mouthed Au hollow capsules. Reproduced from ref. 29 with permission from American Chemical Society.

(a)

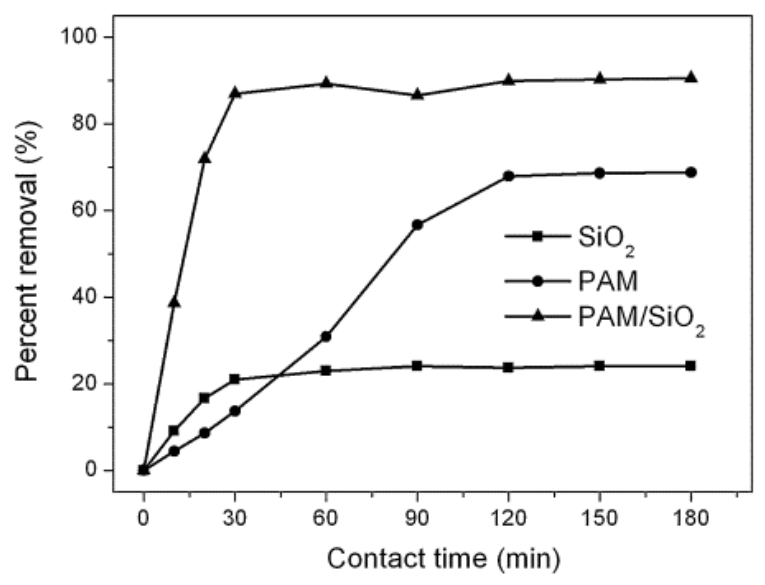

(b)

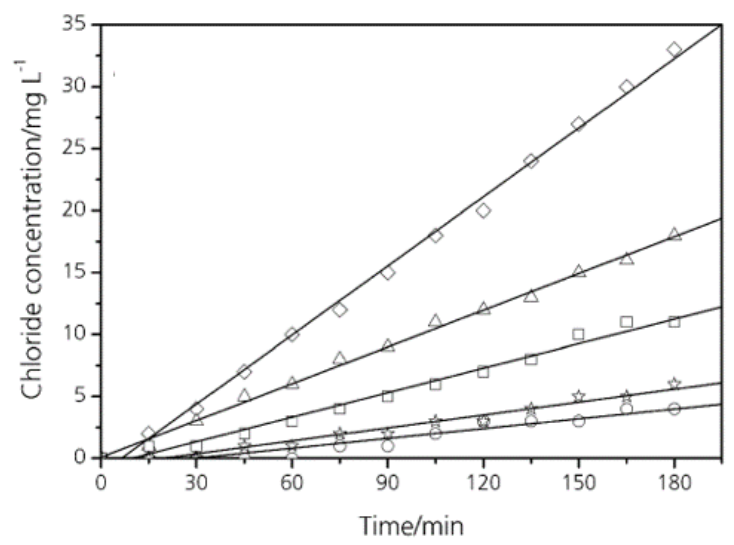

(c)

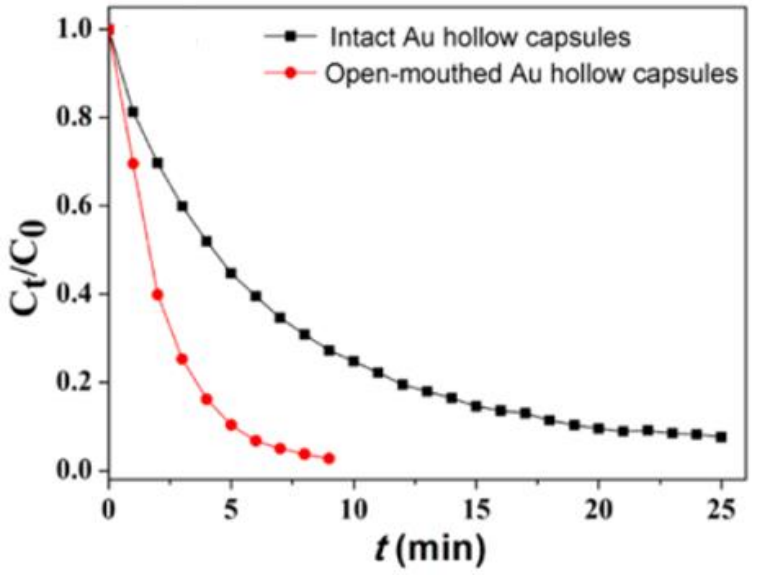


Figure 2. SEM images of capsules from Pickering emulsion templates. (a) $\mathrm{TiO}_{2} /$ poly(styreneco-divinylbenzene) microcapsules (reproduced from ref. 20 with permission from Wiley), (b) $\mathrm{ZnO}$ /polystyrene microcapsules (reproduced from ref. 22 with permission from Springer), (c) porous $\mathrm{TiO}_{2}$ microcapsule after calcination (reproduced from ref. 28 with permission from The Royal Society of Chemistry), (d-f) Au open-mouthed capsules of various shapes (reproduced from ref. 29 with permission from American Chemical Society), (g) non-spherical $\mathrm{SiO}_{2} / \mathrm{PVA}$ capsule prepared from w/o/w emulsion (reproduced from ref. 30 with permission from Wiley), (h) $\mathrm{CaCO}_{3}$ microcapsule after $4^{\text {th }}$ crystallisation (reproduced from ref. 36 with permission from Elsevier), (i) $\mathrm{SiO}_{2}$ capsule from w/o emulsion (reproduced from ref. 43 with permission from American Chemical Society), (j) $\mathrm{SiO}_{2}$ capsule from o/w emulsion (reproduced from ref. 44 with permission from American Chemical Society), (k) $\mathrm{SiO}_{2}$ capsule from w/o emulsion (reproduced from ref. 45 with permission from Wiley), (1) poly(glycidyl methacrylate)/polythioether composite microcapsule (reproduced from ref. 49 with permission from Elsevier), (m) MOF/polystyrene microcapsule (reproduced from ref. 57 with permission from Wiley).

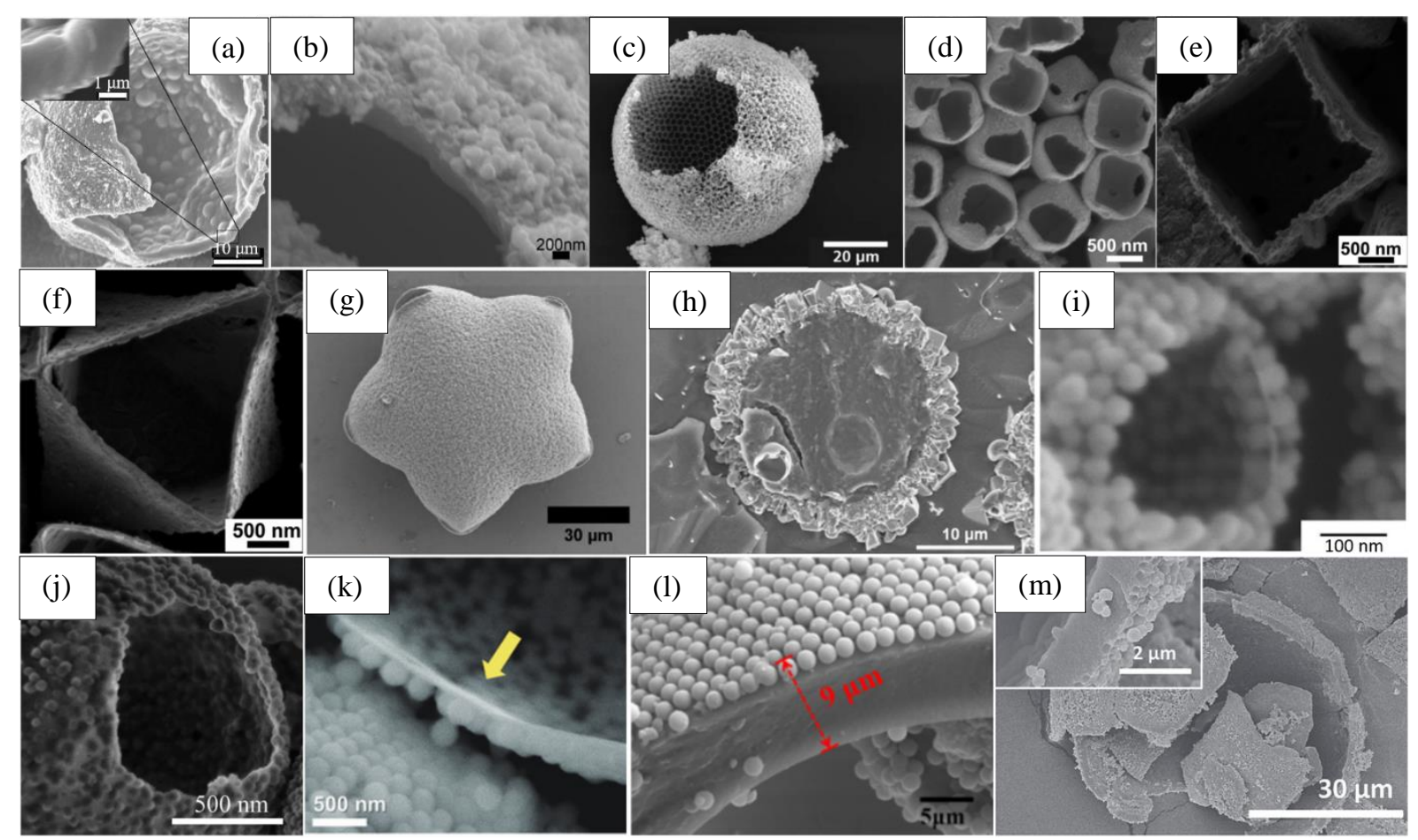


Figure 3. Schematic representation of selected procedures for the preparation of hollow capsules. (a) A w/o emulsion stabilised by silica particles is transferred drop by drop onto a bed of the same particles, followed by rolling to form an oil liquid marble. The marble was dried and cellular capsules were obtained upon evaporation of the liquids. Redrawn from ref. 27 with permission from MDPI. (b) Procedure for preparation of porous $\mathrm{TiO}_{2}$ capsules by liquid phase deposition on polystyrene latex-stabilised Pickering o/w emulsion. After deposition, polystyrene particles were removed by treatment with toluene and calcination removed the oil, leading to porous hollow spheres. Redrawn from ref. 28 with permission from The Royal Society of Chemistry. (c) An o/w Pickering emulsion stabilised with $\mathrm{Cu}_{2} \mathrm{O}$ particles was prepared with wax as the oil phase. After emulsification at $70{ }^{\circ} \mathrm{C}$, the emulsion was cooled to room temperature to solidify the core. A galvanic reaction took place and a film of $\mathrm{Au}$ or $\mathrm{Pt}$ coated the particle surface. Tetrahydrofuran and $\mathrm{HCl}$ were used to remove the wax and $\mathrm{Cu}_{2} \mathrm{O}$ residues, respectively. Various open-mouthed Au or Pt hollow capsules were formed. Redrawn from ref. 29 with permission from American Chemical Society.

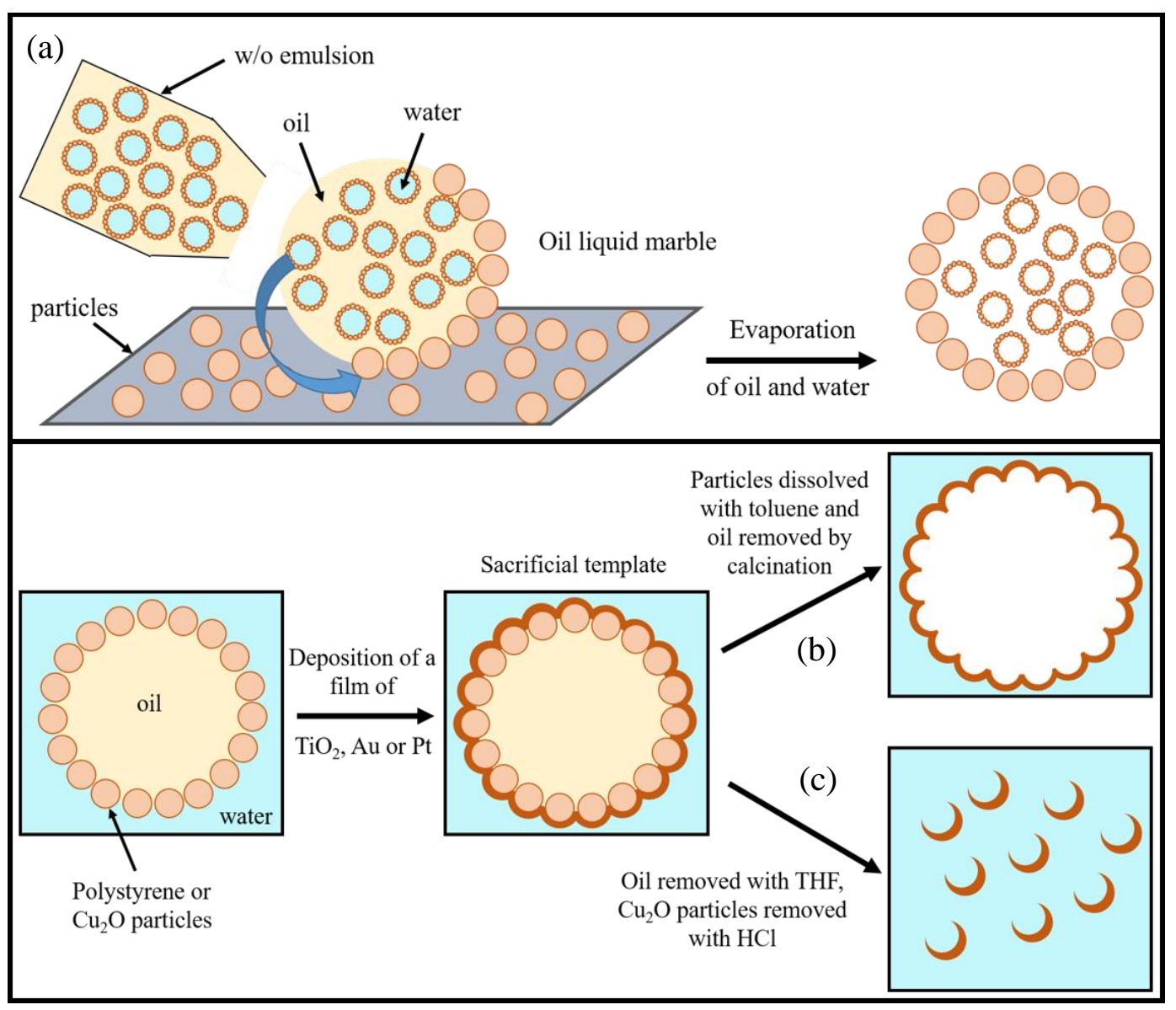


Figure 4. Schematic representation of selected procedures for the preparation of liquid-filled capsules from (a) o/w, (b) w/o and (c) both Pickering emulsions. (a1) An o/w Pickering emulsion is stabilised by polystyrene latex particles. Oil droplets consisted of $n$-octanol, ethyl acetate (EA) and poly(lactic-co-glycolic acid). Aqueous phase was water saturated with EA. Upon dilution, EA molecules diffuse from oil to water and the polymer in oil diffuses outwards getting entrained at the interface and locking the assembled particles. Redrawn from ref. 34 with permission from American Chemical Society. (a2) $\mathrm{CaCO}_{3}$ microparticles were used to emulsify sunflower oil into water to form an o/w emulsion. With added $\mathrm{CO}_{2}$ and $\mathrm{CaCl}_{2}$, interfacial $\mathrm{CaCO}_{3}$ particles act as nucleation site for dissolved calcium and carbonate ions to form a dense $\mathrm{CaCO}_{3}$ shell. Redrawn from ref. 36 with permission from Elsevier. (a3) $\mathrm{CaCO}_{3}$ nanoparticles stabilise an o/w Pickering emulsion. An anionic biopolymer was subsequently added and the $\mathrm{pH}$ was reduced to dissolve the particles. The liberated $\mathrm{Ca}^{2+}$ cross-link the biopolymer at the interface to form a continuous shell enveloping the oil core. Redrawn from ref. 38 with permission from American Chemical Society. (b) A w/o emulsion is stabilised by copolymer particles. Subsequently, a w/o/w emulsion is prepared by adding the w/o emulsion to an aqueous phase containing the same particles. After evaporation of oil, a bilayer of particles forms the shell. Redrawn from ref. 41 with permission from the Royal Society of Chemistry. (c) Either w/o or o/w emulsion is prepared with silica particles. A silica precursor (TMOS, TEOS or PEOS) is either in the oil phase upon emulsification or added after emulsification. The all-silica shell is formed due to hydrolysis and condensation reactions of the silica precursor at the oil-water interface. 
(a)

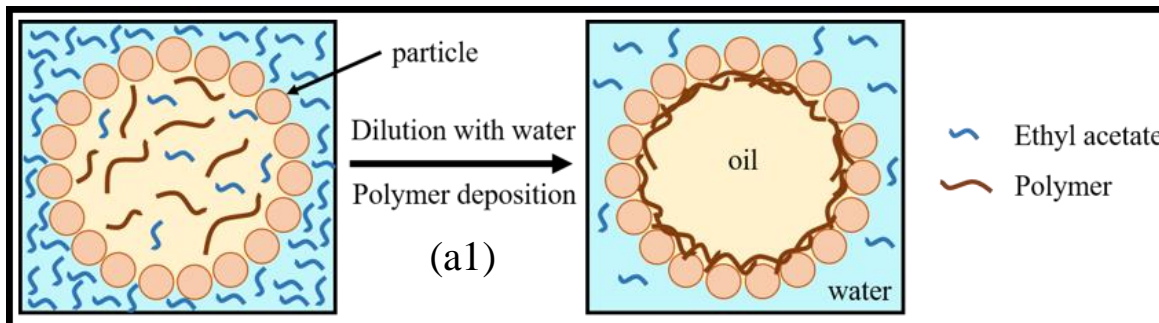

Anionic

biopolymer $\mathrm{Ca}^{2+}$ ions

(b)
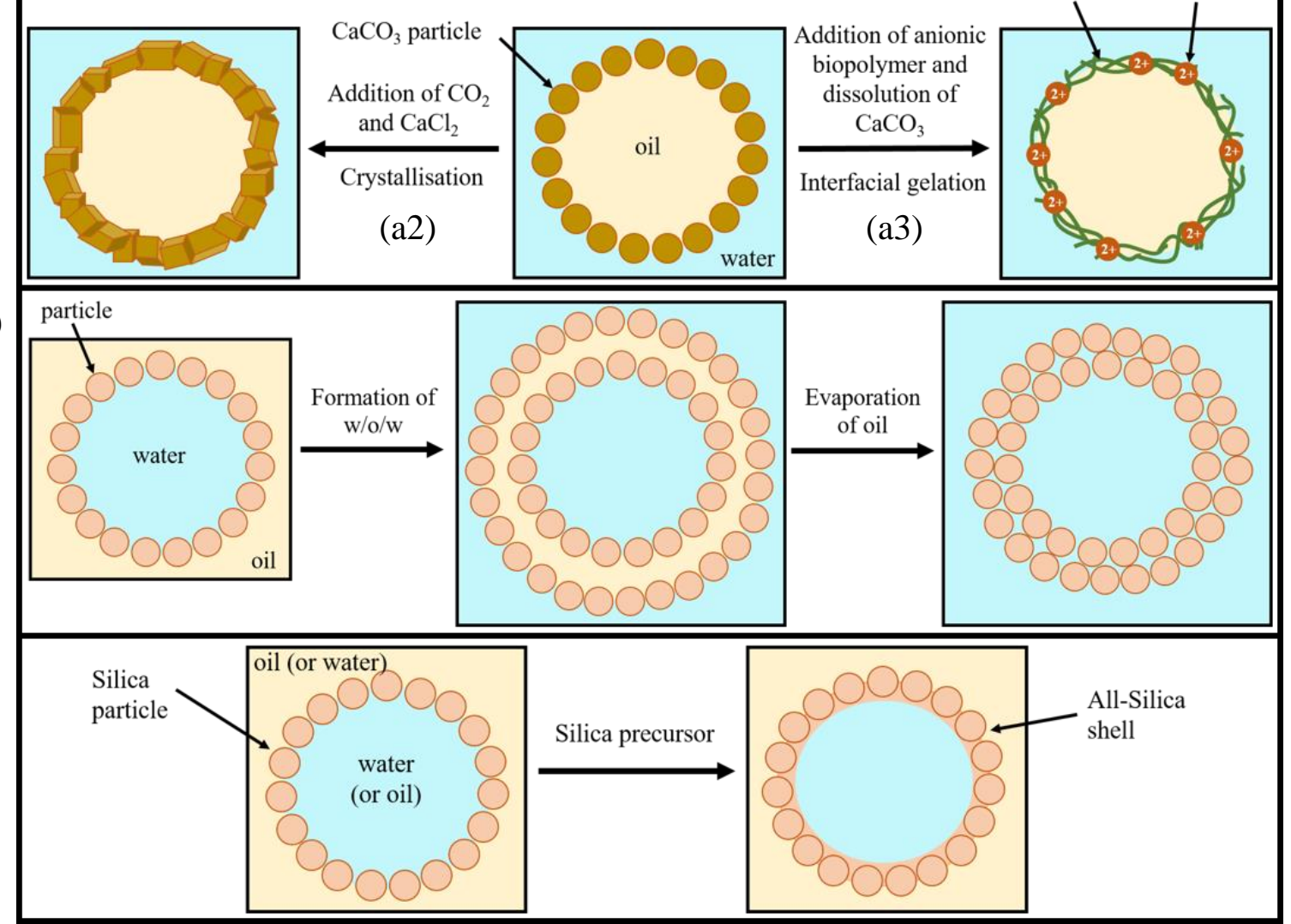
Figure 5. Applications of liquid-filled capsules from Pickering emulsion templates. (a) Ethanol-triggered release profile of methylene blue from all-silica capsules for two silica particle diameters. Reproduced from ref. 45 with permission from Wiley. (b) Reaction rate $v s$ $\mathrm{pH}$ for enzyme-mediated dephosphorylation in (1) copolymer-modified all-silica capsules, (2) all-silica capsules and (3) bulk water. Reproduced from ref. 46 with permission from Springer Nature. (c) Amount of phenol removed after passing it through a column packed either with IL-containing polyurea/rGO capsules (blue trace) or with the capsule shells after extraction of IL (red trace). Reproduced from ref. 51 with permission from American Chemical Society. (d) Specific capacitance $v s$ scan rate for coin-cell supercapacitors of IL-containing polyurea/rGO capsules, polyurea/rGO capsule shells and a commercial porous carbon at two temperatures. Reproduced from ref. 52 with permission from American Chemical Society. (e) Fraction of oil red $\mathrm{O}$ released $v s$ time from $\mathrm{MOF} /$ polystyrene capsules (black squares) or polystyrene-only capsules (red circles). Reproduced from ref. 57 with permission from Wiley. (f) Evaporation profiles of non-encapsulated turpentine oil (squares, circles, triangles) and turpentine oil encapsulated in a cellulose/polydopamine capsule (inverted triangles). Reproduced from ref. 59 with permission from Elsevier.

(a)

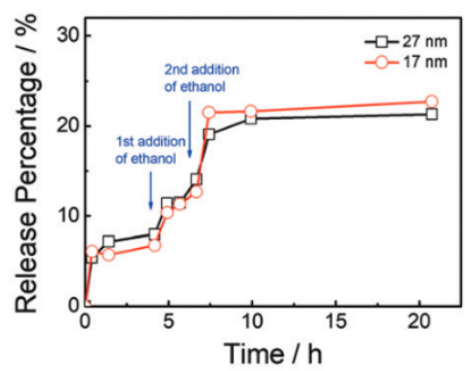

(d)

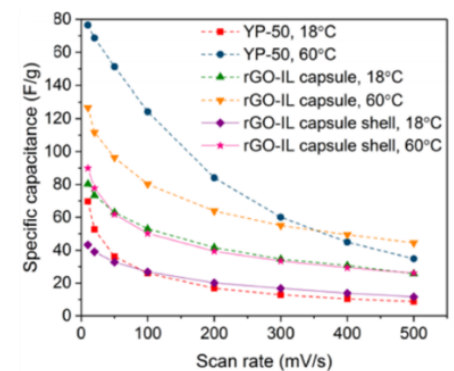

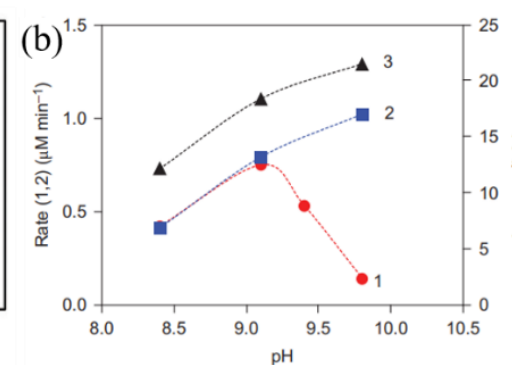

(e)

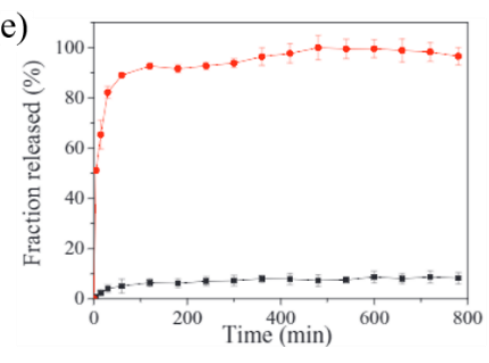

(c)

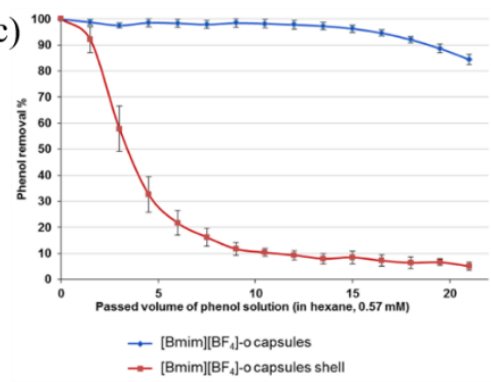

(f)

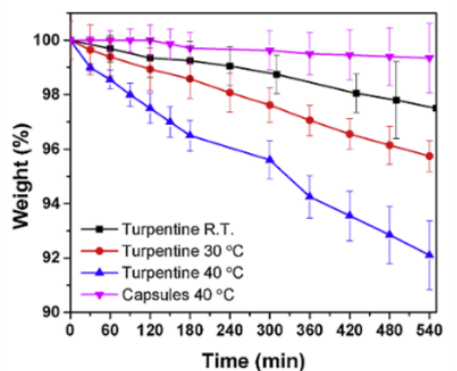


Table 1. System composition and method to prepare capsules from Pickering emulsion templates.

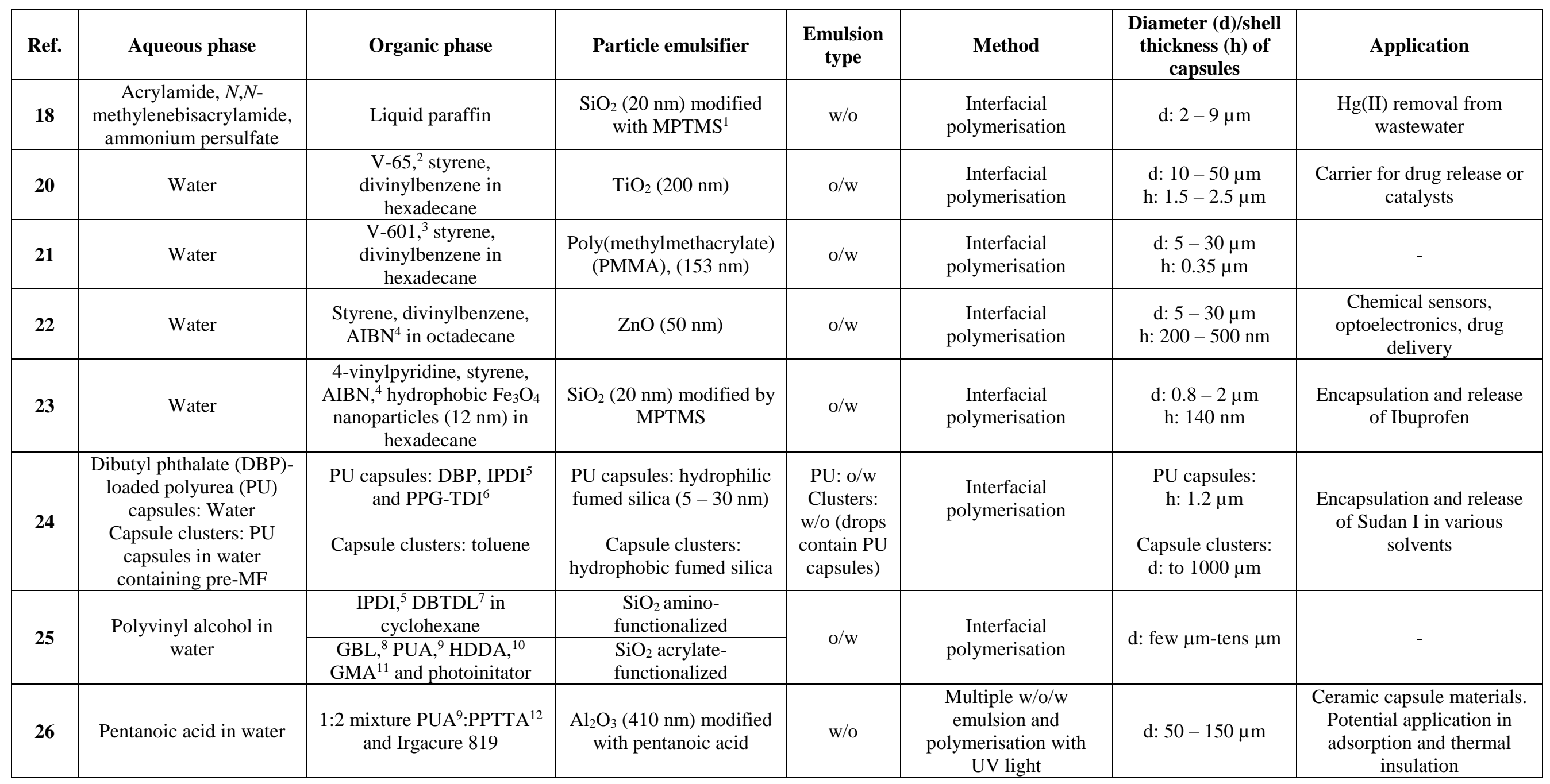




\begin{tabular}{|c|c|c|c|c|c|c|c|}
\hline 27 & Water & $\begin{array}{c}\text { Dichloromethane (DCM), } \\
\text { poly(L-lactic acid) }\end{array}$ & $\mathrm{SiO}_{2}(20 \mathrm{~nm})$ modified & w/o & Oil liquid marbles & $\mathrm{d}: \sim 2.5 \mathrm{~mm}$ & $\begin{array}{l}\text { Sustained drug release } \\
\text { (enrofloxacin) }\end{array}$ \\
\hline 28 & Water & 1-octanol & $\begin{array}{c}\text { Polyelectrolyte } \\
\left(\text { PDADMAC }^{13} \text { and }\right. \\
\left.\text { PAA }^{14}\right) \text {-coated PS }{ }^{15} \text { latex } \\
(2 \mu \mathrm{m})\end{array}$ & $\mathrm{o} / \mathrm{w}$ & $\begin{array}{c}\text { Liquid phase } \\
\text { deposition of } \mathrm{TiO}_{2}\end{array}$ & $\mathrm{~d}: 50-150 \mu \mathrm{m}$ & Photocatalysis \\
\hline 29 & Water & Paraffin wax & $\begin{array}{c}\mathrm{Cu}_{2} \mathrm{O}(820 \mathrm{~nm}) \text { of various } \\
\text { shapes }\end{array}$ & $\mathrm{o} / \mathrm{w}$ & Galvanic reaction & $\begin{array}{c}\text { d open-mouthed } \\
(\mathrm{Au}): 835 \mathrm{~nm} \\
\text { h: } 33 \mathrm{~nm}(\mathrm{Au}), 10 \\
\mathrm{~nm}(\mathrm{Pt})\end{array}$ & $\begin{array}{l}\text { Catalytic reduction of } 4- \\
\text { nitrophenol }\end{array}$ \\
\hline 30 & Water, polyvinyl alcohol & Toluene & $\mathrm{SiO}_{2}(15 \mathrm{~nm})$ modified & $\mathrm{w} / \mathrm{o} / \mathrm{w}$ & Evaporation & $\mathrm{d}: \sim 40 \mu \mathrm{m}$ & - \\
\hline 31 & Water & Ethyl acetate, AIBN $^{4}$ & Microgel (84 nm) & $\mathrm{o} / \mathrm{w}$ & Microgel cross-linking & $\mathrm{d}: \sim 1 \mu \mathrm{m}$ & Release of FITC-dextran \\
\hline 32 & Water with electrolytes & Dodecane & $\begin{array}{c}\mathrm{TiO}_{2}(<25 \mathrm{~nm}) \text { modified } \\
\text { with ODPA }\end{array}$ & $\mathrm{o} / \mathrm{w}$ & $\begin{array}{l}\text { Deposition of polymer } \\
\text { layers }\end{array}$ & $\mathrm{d}: 3-5 \mu \mathrm{m}$ & Wastewater purification \\
\hline 33 & Water & $\begin{array}{c}\text { Perfluoroheptane or } \\
\text { heptane or butyl acetate or } \\
\text { chloroform }\end{array}$ & $\mathrm{SiO}_{2}(15 \mathrm{~nm})$ & $\mathrm{o} / \mathrm{W}$ & $\begin{array}{c}\text { Layer-by-layer } \\
\text { assembly with } \\
\text { PDADMAC }^{13} \text { and } \\
\text { PSS }^{17} \text { or with } \mathrm{SiO}_{2}\end{array}$ & $\mathrm{~h}: 60-80 \mathrm{~nm}$ & $\begin{array}{c}\text { Encapsulation of } \\
\text { hydrophobic materials }\end{array}$ \\
\hline 34 & $\begin{array}{l}\text { Water saturated with } \\
\text { ethyl acetate (EA) }\end{array}$ & $\begin{array}{l}\text { Octanol, EA, poly(lactic-co- } \\
\text { glycolic acid) (PLGA) }\end{array}$ & $\begin{array}{c}\text { PS latex coated with } \\
\text { carboxylic acid }(260 \mathrm{~nm})\end{array}$ & $\mathrm{o} / \mathrm{W}$ & $\begin{array}{c}\text { Deposition of polymer } \\
\text { layers }\end{array}$ & $\mathrm{d}: 3-4 \mu \mathrm{m}$ & $\begin{array}{c}\text { Encapsulation of } \\
\text { hydrophobic actives }\end{array}$ \\
\hline 35 & $\begin{array}{l}\text { Water, } \mathrm{NaCl} \text { and } \\
\text { Carbopol 971P }\end{array}$ & $\begin{array}{c}\text { Tetradecane, limonene, } \\
\text { benzyl salicylate or } \\
\text { citronellol }\end{array}$ & $\begin{array}{l}\mathrm{SiO}_{2}(3.5 \mu \mathrm{m}) \text { modified } \\
\text { with potassium oleate }\end{array}$ & $\mathrm{o} / \mathrm{w}$ & Deposition of polymer & $\mathrm{d}: \sim 20 \mu \mathrm{m}$ & $\begin{array}{c}\text { Encapsulation and release } \\
\text { of fragrances }\end{array}$ \\
\hline 36 & $\begin{array}{c}\mathrm{pH}=8.5 \text { buffer } \\
\text { (ammonia and } \\
\text { ammonium chloride) }\end{array}$ & Sunflower oil & $\begin{array}{c}\mathrm{CaCO}_{3} \text { (length: } 2 \mu \mathrm{m}, \\
\text { width: } 1 \mu \mathrm{m})\end{array}$ & $\mathrm{o} / \mathrm{w}$ & Crystallisation & $\begin{array}{l}\mathrm{d}: 20-40 \mu \mathrm{m} \\
\mathrm{h}: \text { to } 2.5 \mu \mathrm{m}\end{array}$ & $\begin{array}{c}\text { Encapsulation and release } \\
\text { of limonene }\end{array}$ \\
\hline 37 & Hot agarose solution & Tricaprylin & $\begin{array}{l}\text { Polymeric microrods }{ }^{18} \\
\text { (length: } 10-70 \mu \mathrm{m} \text {, } \\
\text { diameter: } 0.4-2 \mu \mathrm{m} \text { ) }\end{array}$ & w/o & $\begin{array}{l}\text { Gelation of core and } \\
\text { cross-linking of } \\
\text { interface }\end{array}$ & $\mathrm{d}: \sim 200 \mu \mathrm{m}$ & $\begin{array}{c}\text { Delivery vehicles for } \\
\text { controlled release of drugs, } \\
\text { cosmetics }\end{array}$ \\
\hline
\end{tabular}




\begin{tabular}{|c|c|c|c|c|c|c|c|}
\hline 38 & Water & $\begin{array}{c}\text { Palm olein or cyclohexane } \\
\text { or dichloromethane or } \\
\text { toluene }\end{array}$ & $\mathrm{CaCO}_{3}(100-400 \mathrm{~nm})$ & $\mathrm{o} / \mathrm{w}$ & Gelation of interface & $\begin{array}{c}\mathrm{d}: 1-280 \mu \mathrm{m} \\
\mathrm{h}: 1 \mu \mathrm{m} \text { (for } 2 \mu \mathrm{m} \\
\text { capsule) }\end{array}$ & $\begin{array}{c}\text { Controlled release or } \\
\text { chemical-on-demand } \\
\text { applications }\end{array}$ \\
\hline 39 & $\begin{array}{l}\text { Water with } \mathrm{CaCO}_{3}(90- \\
\qquad 220 \mathrm{~nm})\end{array}$ & Hexadecane & $\begin{array}{c}\text { Cellulose nanocrystals } \\
\text { (length: } 190 \mathrm{~nm} \text {, width: } 9 \\
\mathrm{~nm} \text { ) }\end{array}$ & $\mathrm{o} / \mathrm{w}$ & $\begin{array}{c}\text { Gelation of interface } \\
\text { and water }\end{array}$ & $\begin{array}{c}\mathrm{d}: 85 \mu \mathrm{m} \text { (contain } \\
12 \text { oil drops of } 15 \\
\mu \mathrm{m})\end{array}$ & $\begin{array}{c}\text { Encapsulation and release } \\
\text { of Nile red }\end{array}$ \\
\hline 40 & Water & Refined palm oil & Chitosan $(500-1800 \mathrm{~nm})$ & $\mathrm{o} / \mathrm{w}$ & $\begin{array}{l}\text { Ionic cross-linking with } \\
\mathrm{Na} \text { tripolyphosphate }\end{array}$ & $\mathrm{d}: 90-137 \mu \mathrm{m}$ & $\begin{array}{l}\text { Encapsulation and oil } \\
\text { release of tocotrienol }\end{array}$ \\
\hline 41 & Water & Dichloromethane & $\begin{array}{l}\text { Particles from } \\
\text { nanoprecipitation: methyl } \\
\text { methacrylate-methacrylic } \\
\text { acid copolymer }(200 \mathrm{~nm})\end{array}$ & w/o/w & $\begin{array}{c}\text { Multiple emulsion } \\
\text { template and } \\
\text { subsequent evaporation } \\
\text { of oil }\end{array}$ & $\mathrm{d}: 5-120 \mu \mathrm{m}$ & $\begin{array}{c}\text { Swift release of capsule } \\
\text { content can be triggered by } \\
\text { pH change }\end{array}$ \\
\hline 42 & $\begin{array}{l}\text { Water, Pluronic } \\
\text { copolymer }\end{array}$ & Fluorinated oil, surfactant & $\beta$-cyclodextrin $(10 \mathrm{~nm})$ & $\mathrm{w} / \mathrm{o} / \mathrm{w}$ & Evaporation of oil & $\begin{array}{l}\mathrm{d}: \sim 50 \mu \mathrm{m} \\
\mathrm{h}: \sim 40 \mathrm{~nm}\end{array}$ & $\begin{array}{c}\text { Dye encapsulation and } \\
\text { release }\end{array}$ \\
\hline 43 & Aqueous $\mathrm{HCl}(\mathrm{pH}=1)$ & Toluene & $\begin{array}{l}\mathrm{SiO}_{2}(50 \mathrm{~nm}) \text { modified } \\
\text { with } \mathrm{C}_{18} \text { silane }\end{array}$ & w/o & $\begin{array}{l}\text { Sol-gel process with } \\
\text { PEOS }^{19}\end{array}$ & $\begin{array}{c}\text { d: few hundred nm- } \\
\mu \mathrm{m} \\
\mathrm{h}: 10-15 \mathrm{~nm} \\
\end{array}$ & $\begin{array}{c}\text { Dye release experiments. } \\
\text { Used to encapsulate } \\
\text { aggressive fluids }\end{array}$ \\
\hline 44 & Water & $\begin{array}{l}\text { Toluene or hexadecane or } \\
\text { hexyl acetate with PEOS }\end{array}$ & $\begin{array}{l}\mathrm{SiO}_{2} \text { modified with } \mathrm{C}_{18} \\
\quad \text { silane }(120 \mathrm{~nm})\end{array}$ & $\mathrm{o} / \mathrm{w}$ & $\begin{array}{l}\text { Sol-gel process with } \\
\text { PEOS }^{19}\end{array}$ & $\mathrm{~d}: 1-2 \mu \mathrm{m}$ & $\begin{array}{c}\text { Encapsulation and release } \\
\text { of liquids under isothermal } \\
\text { conditions }\end{array}$ \\
\hline 45 & Aqueous ammonia & Toluene & $\begin{array}{l}\mathrm{SiO}_{2}(50,120,230 \mathrm{~nm}) \\
\text { modified with DCDMS }\end{array}$ & w/o & $\begin{array}{l}\text { Sol-gel process with } \\
\text { TEOS }^{21}\end{array}$ & $\begin{array}{l}\mathrm{d}: 1 \mu \mathrm{m}(120 \mathrm{~nm} \\
\text { particles }),<500 \mathrm{~nm} \\
(50 \mathrm{~nm} \text { particles }) \\
\mathrm{h}: 17-27 \mathrm{~nm}\end{array}$ & $\begin{array}{l}\text { Encapsulation and release } \\
\text { of methylene blue }\end{array}$ \\
\hline 46 & Water & Dodecane & $\mathrm{SiO}_{2}(25 \mathrm{~nm})$ & w/o & $\begin{array}{l}\text { Sol-gel process with } \\
\text { TMOS }^{22} \text { and } \\
\text { subsequent } \\
\text { functionalisation of } \\
\text { silica }\end{array}$ & $\mathrm{d}: \sim 100 \mu \mathrm{m}$ & $\begin{array}{l}\text { Release studies of calcein, } \\
\text { rhodamine } 6 \mathrm{G} \text { and } \\
\text { myoglobin. Release is pH- } \\
\text { sensitive }\end{array}$ \\
\hline 47 & Water $(\mathrm{pH}=1)$ & $\begin{array}{c}\text { Toluene with TEOS } \\
\text { TBOS }^{23} \text { or }\end{array}$ & $\begin{array}{c}\text { Cellulose grafted with } \\
\text { cinnamate (length: } 139 \\
\text { nm, width: } 8 \mathrm{~nm} \text { ) }\end{array}$ & w/o & $\begin{array}{l}\text { Sol-gel process with } \\
\text { TEOS }^{21} \text { and } \mathrm{TBOS}^{23}\end{array}$ & $\mathrm{~h}: 1.2 \mu \mathrm{m}$ & $\begin{array}{c}\text { Encapsulation of } \\
\text { rhodamine B or fluorescent } \\
\text { DNA }\end{array}$ \\
\hline 48 & Water $(\mathrm{pH}=2-3)$ & $\begin{array}{l}\text { IPDI }{ }^{5} \text { diphenyl methane } \\
\text { diisocyanate (MDI) }\end{array}$ & Lignin $(\sim 300 \mu \mathrm{m})$ & $\mathrm{o} / \mathrm{w}$ & $\begin{array}{c}\text { Interfacial } \\
\text { polymerisation }\end{array}$ & $\begin{array}{c}\mathrm{d}: 40-117 \mu \mathrm{m} \\
\mathrm{h}: 4.5 \mu \mathrm{m}\end{array}$ & $\begin{array}{l}\text { Self-healing coating with } \\
\text { anti-corrosive properties }\end{array}$ \\
\hline 49 & Water, photoinitiator & IPDI, ${ }^{5} \mathrm{TTT},{ }^{24} \mathrm{TMMP}^{25}$ & $\begin{array}{c}\text { Poly(glycidyl } \\
\text { methacrylate })(1 \mu \mathrm{m})\end{array}$ & $\mathrm{o} / \mathrm{w}$ & $\begin{array}{c}\text { Interfacial } \\
\text { polymerisation }\end{array}$ & $\begin{array}{c}\mathrm{d}: \sim 100 \mu \mathrm{m} \\
\mathrm{h}: 9 \mu \mathrm{m}\end{array}$ & Self-healing coating \\
\hline 50 & $\begin{array}{l}\text { Diethylenetriamine, } \\
\mathrm{GuHCl}^{26}\end{array}$ & $\begin{array}{l}\text { Decalin, hexadecane, } \\
\text { polyisobutylene }\end{array}$ & Clay modified (few $\mu \mathrm{m}$ ) & polar/o & $\begin{array}{c}\text { Interfacial } \\
\text { polymerisation }\end{array}$ & $\mathrm{d}: 10 \mu \mathrm{m}$ & $\begin{array}{c}\text { Encapsulation of } \\
\text { hydrophilic payloads }\end{array}$ \\
\hline
\end{tabular}




\begin{tabular}{|c|c|c|c|c|c|c|c|}
\hline \multirow{2}{*}{51} & Aqueous $\mathrm{Na}_{2} \mathrm{CO}_{3}$ & $\begin{array}{l}\text { 1,6-diisocyanatohexane, } \\
\text { ionic liquid }\end{array}$ & $\begin{array}{l}\text { Graphene oxide } \\
\text { nanosheets, GO } \\
\text { (diameter: microns, } \\
\text { height: } 1 \mathrm{~nm} \text { ) }\end{array}$ & $\mathrm{IL} / \mathrm{W}$ & $\begin{array}{c}\text { Interfacial } \\
\text { polymerisation }\end{array}$ & \multirow{2}{*}{$\begin{array}{c}\mathrm{d} \text { : various } \\
\text { depending on } \\
\text { monomer and ionic } \\
\text { liquid but around } \\
40 \mu \mathrm{m}\end{array}$} & \multirow{2}{*}{$\begin{array}{c}\text { Active column material for } \\
\text { extraction of phenol from } \\
\text { oil }\end{array}$} \\
\hline & $\begin{array}{c}\text { Ionic liquid and } \\
\text { ethylenediamine (EDA) }\end{array}$ & Octane & $\begin{array}{l}\text { GO modified with } \mathrm{C}_{18} \\
\text { amine }\end{array}$ & IL/o & $\begin{array}{c}\text { Interfacial } \\
\text { polymerisation }\end{array}$ & & \\
\hline 52 & Aqueous $\mathrm{Na}_{2} \mathrm{CO}_{3}$ & $\begin{array}{l}\text { Ionic liquid, hexamethylene } \\
\text { diisocyanate }\end{array}$ & GO nanosheets & $\mathrm{IL} / \mathrm{W}$ & $\begin{array}{c}\text { Interfacial } \\
\text { polymerisation }\end{array}$ & $\begin{array}{l}\mathrm{d}: 25-100 \mu \mathrm{m} \\
\mathrm{h}: 10-15 \mu \mathrm{m}\end{array}$ & $\begin{array}{l}\text { Electrochemical double- } \\
\text { layer capacitors }\end{array}$ \\
\hline 53 & Water & $\begin{array}{c}\text { Aliphatic isocyanate, } \\
\text { limonene }\end{array}$ & $\begin{array}{l}\text { Coacervate droplets from } \\
\text { electrostatic interaction } \\
\text { between gelatin and } \\
\text { Acacia gum }\end{array}$ & $\mathrm{o} / \mathrm{w}$ & $\begin{array}{c}\text { Interfacial } \\
\text { polymerisation }\end{array}$ & $\mathrm{d}: \sim 500 \mu \mathrm{m}$ & - \\
\hline 55 & Water (pH 7) & $\begin{array}{l}5 \text { volatile fragrance } \\
\text { compounds, aliphatic } \\
\text { polyisocyanate }\end{array}$ & $\begin{array}{c}\mathrm{SiO}_{2} \text { modified with } \\
\text { amino groups }(10-20 \mathrm{~nm}) \\
\text { and fumed silica }(5-30 \\
\mathrm{nm})\end{array}$ & $\mathrm{o} / \mathrm{w}$ & $\begin{array}{c}\text { Interfacial } \\
\text { polymerisation }\end{array}$ & $\mathrm{d}: \sim 15 \mu \mathrm{m}$ & $\begin{array}{c}\text { Permeability measurements } \\
\text { by thermogravimetry }\end{array}$ \\
\hline 56 & Water & $\begin{array}{l}\text { Styrene, divinylbenzene, } \\
\text { AIBN },{ }^{4} \text { dodecanol }\end{array}$ & $\begin{array}{c}\text { Poly(glycidyl } \\
\text { methacrylate), PGMA } \\
(1.1 \mu \mathrm{m})\end{array}$ & $\mathrm{o} / \mathrm{w}$ & $\begin{array}{c}\text { Interfacial } \\
\text { polymerisation }\end{array}$ & $\mathrm{d}: 40 \mu \mathrm{m}$ & $\begin{array}{l}\text { Phase change material for } \\
\text { thermal energy storage }\end{array}$ \\
\hline 57 & Water & $\begin{array}{c}\text { Dodecane, styrene, } \\
\text { divinylbenzene, initiator }\end{array}$ & $\begin{array}{c}\text { Metal-organic } \\
\text { framework, MOF (350 } \\
\mathrm{nm})\end{array}$ & $\mathrm{o} / \mathrm{w}$ & $\begin{array}{c}\text { Interfacial } \\
\text { polymerisation }\end{array}$ & $\begin{array}{l}\mathrm{d}: 41 \mu \mathrm{m} \\
\mathrm{h}: 1.8 \mu \mathrm{m}\end{array}$ & $\begin{array}{l}\text { Oil red O encapsulation and } \\
\text { release. Addition of acid } \\
\text { dissolves the particles and } \\
\text { releases dye rapidly }\end{array}$ \\
\hline
\end{tabular}




\begin{tabular}{|c|c|c|c|c|c|c|c|}
\hline 58 & Water & $\begin{array}{l}\text { Hexadecane, styrene, } \\
\text { divinylbenzene, AIBN }{ }^{4}\end{array}$ & $\begin{array}{c}\text { Peroxidized latex } \\
\text { particles }^{27}(100-200 \mathrm{~nm})\end{array}$ & $\mathrm{o} / \mathrm{w}$ & $\begin{array}{c}\text { Interfacial } \\
\text { polymerization }\end{array}$ & $\begin{array}{l}\mathrm{d}: \sim 10 \mu \mathrm{m} \\
\mathrm{h}: \sim 1.5 \mu \mathrm{m}\end{array}$ & - \\
\hline 59 & Water & $\begin{array}{l}\text { Oil of turpentine, } 2,4-\mathrm{D}^{28} \text {, } \\
\text { butanol }\end{array}$ & $\begin{array}{l}\text { Cellulose modified with } \\
\text { cinnamoyl chloride (113 } \\
\mathrm{nm})\end{array}$ & $\mathrm{o} / \mathrm{w}$ & $\begin{array}{l}\text { Interfacial } \\
\text { polymerisation after } \\
\text { adding dopamine }\end{array}$ & $\begin{array}{c}\mathrm{d}: 2-6 \mu \mathrm{m} \\
\mathrm{h}: 100-200 \mathrm{~nm}\end{array}$ & $\begin{array}{l}\text { Encapsulation of 2,4-D } \\
\text { (herbicide) }\end{array}$ \\
\hline 60 & Water, isopropanol & Tricaprylin, glutaraldehyde & $\begin{array}{l}\text { C nanotubes modified } \\
\text { with amine (length } \sim 100 \\
\text { nm, width few nm) }\end{array}$ & w/o & $\begin{array}{l}\text { Cross-linking at } \\
\text { interface }\end{array}$ & $\mathrm{d}: 1-20 \mu \mathrm{m}$ & Catalysis \\
\hline 61 & Water $(\mathrm{pH}=10)$ & $\begin{array}{l}\text { Peppermint oil, } \\
\text { cinnamaldehyde }\end{array}$ & $\begin{array}{l}\mathrm{SiO}_{2} \text { modified with amine } \\
\quad(\sim 150 \mathrm{~nm})\end{array}$ & $\mathrm{o} / \mathrm{w}$ & $\begin{array}{c}\text { Surface amines on } \\
\text { particles react with } \\
\text { cinnamaldehyde in oil }\end{array}$ & $\mathrm{d}: \sim 7 \mu \mathrm{m}$ & Kill bacterial cells \\
\hline 62 & Water $(\mathrm{pH}=8)$ & Toluene & $\begin{array}{c}\mathrm{SiO}_{2} \text { positively and } \\
\text { negatively charged } \\
\text { nitrophenylene-doped } \\
(100 \mathrm{~nm})\end{array}$ & $\mathrm{o} / \mathrm{w}$ & Electrostatic attraction & $\mathrm{d}: 200-700 \mathrm{~nm}$ & $\begin{array}{c}\text { Encapsulation and release } \\
\text { of Nile red }\end{array}$ \\
\hline
\end{tabular}

1. Methacryloxypropyltrimethoxysilane, 2. 2,2'-Azobis(2,4-dimethyl valeronitrile), 3. Dimethyl-2,2-azobis(isobutyrate), 4. 2,2'-azobisisobutyronitrile, 5. Isophorone diisocyanate, 6. Tolylene 2,4-diisocyanate-terminated polypropylene glycol, 7. Dibutyltin dilaurate, 8. $\gamma$-butyrolactone, 9. Polyurethane acrylate, 10. Hexadiol diacrylate, 11. Glycidyl methacrylate, 12. Ethoxylated pentaerythritol tetraacrylate, 13. Poly(diallyldimethylammonium chloride), 14. poly(acrylic acid), 15. Polystyrene, 16. $n$-octadecylphosphonic acid, 17. poly(sodium styrenesulfonate), 18. Prepared from SU-8 25 photoresist epoxy resin, 19. Hyperbranched polyethoxysiloxane, 20. Dichlorodimethylsilane, 21. Tetraethyl orthosilicate, 22. Tetramethoxysilane, 23. Tetrabutyl orthosilicate, 24. 1,3,5-tri2-propenyl-1,3,5-triazine-2,4,6 (1H, 3H, 5H)-trione, 25. Trimethylolpropane tris (3-mercaptopropionate), 26. Guanidinium chloride, 27. Prepared through emulsion polymerisation with amphiphilic polyperoxide copolymer poly[ $N$-(t-butylperoxymethyl) acrylamide]-co-maleic anhydride, 28. 2,4dichlorophenoxyacetic acid. 